\title{
Em meio às trilhas do Rio de Janeiro e de Trieste com a Lírica urbana de Reynaldo Valinho Alvarez e Umberto Saba
}

\author{
Delia Cambeiro ${ }^{1}$ \\ Universidade do Estado do Rio de Janeiro \\ delia.cambeiro@gmail.com
}

RESUMO: A cidade na lírica urbana tem sido objeto de nossas pesquisas há algum tempo, e vimos desenvolvendo-a em artigos, prefácios, além da publicação e apresentação de livros com tal temática. Nesse breve trabalho, propomos dois poetas que se nos mostram especiais no que toca à literatura como manifestação de anseios, angústias ou maravilhamentos do ser humano habitante da urbe. Com as experiências estéticas de Valinho e de Saba, desejamos refletir de que forma eles captam as nuances da vida na cidade; também indagar sobre a intensidade lírica de suas poesias, no difícil caminhar do homem citadino, simbolicamente observado, seja em exílio de sofrimento, num temido locus horrendus, seja em reinado de felicidade, num sonhado locus amoenus. Para tal questionamento, utilizaremos alguns poemas dos autores propostos para estudo e títulos teóricos sobre a cidade.

Palavras-chave: Teorias da Cidade. Lírica Urbana. Reynaldo Valinho Alvarez. Umberto Saba. Rio de Janeiro. Trieste.

ABSTRACT: The city in the urban lyric has been the object of our research for some time, being developed in articles and also in published books on that theme. In this brief article, we discuss two poets that stand out in their approach to literature as a manifestation of thelonging, distress and wonder of the human being that inhabit the urbe. With the aesthetical experience of Valinho and Saba, we wish to reflect upon the way both capture the nuances of city life, and also question the lyrical intensity of their poetry, the hardships of the city man, symbolically observed in an exile of suffering - a dreafullocus borrendus or in a reign of happiness - a locus amoenus. For the purposes of this questioning, we will work with some poems by the proposed authors ofstudies and theoretical titles on the city.

Keywords: City Theories. Urban Lyric. Reynaldo Valinho Alvarez. Umberto Saba. Rio de Janeiro. Trieste.

Pós-Doutorado em Literatura Comparada na Universidade A Coruña (UDC), Espanha. Professora Associado da UERJ 


\section{I - Ao encontro das teorias sobre as cidades}

O carioca Reynaldo Valinho Alvarez (1931) e o triestino Umberto Poli, conhecido como o poeta Umberto Saba (1883-1957), são nomes que sedimentam, com raro vigor, a lírica urbana sobre suas cidades de nascimento. Tanto o Rio de Janeiro como Trieste, apesar de distantes em geografia, têm sapatas comuns construídas em alto grau de beleza e de domínio da forma.

Antes de desenvolvermos o trabalho sobre os iluminados poetas, faremos sintética orientação teórica sobre o tema cidade, a fim de iniciarmos o percurso investigativo, que nos levará ao encontro de um lírico e melancólico $\mathrm{Eu}$ flâneur revelado nas entrelinhas dos poemas escolhidos para estudo. Para tal objetivo, alternaremos com a lírica urbana alguns conceitos teóricos sobre a cidade que ajudarão na leitura dos poemas urbanos, sem comprometer, entretanto, o privilégio da poesia, foco inegável deste ensaio.

Decidimos pelo diálogo entre literatura e ciência, ou seja, entre texto imaginativo e teorias da cidade, devido à sugestiva palavra de Tzvetan Todorov, que, em seu $A$ literatura em perigo (2007, pp.28-29-31), avalia a contribuição de tal "conversa" interdisciplinar. O mestre búlgaro recentemente falecido, em 7 de fevereiro de 2017 -, ao se referir às possíveis vozes complementares do texto literário, ensina-nos a delimitar, porém, o campo de tal interferência e importância, pois, segundo ele, "[...] em nenhum caso o estudo desses meios de acesso pode substituir o sentido da obra, que é o seu fim, [...] a própria significação dessa busca". Por tratar-se, evidentemente, de uma fala complementar e argumentativa, ele afirma que "[...] nenhuma diz respeito ao que falam as obras em si, seu sentido, o mundo que elas evocam". De fato, não dizem respeito especificamente à arte poética, entretanto, aqui a aplicamos, pois acreditamos que muito complementam, argumentam e dizem sobre o tema. 
Antes de entrarmos nas sendas dos poemas de Valinho e de Saba, endereçamos nosso foco para o tema proposto e afirmamos que refletir sobre a cidade não se mostra uma fácil tarefa, apesar de muito discurso teórico já estar registrado em várias línguas e em inúmeras traduções para o português. O fenômeno cidade, devemos sublinhar, não é preocupação exclusiva dos séculos XX e/ou XXI, nem foram esses os períodos que colocaram na berlinda a observação e a história de tão instigante geografia. As raízes da cidade brotaram na mais remota vereda do tempo, como bem nos orienta Joel Kotkin, em $A$ história da cidade: uma história global. Ele assim nos esclarece, quanto à universalidade da experiência do homem na cidade:

A evolução da cidade materializa a história da humanidade. [...] A maior criação da humanidade foi suas cidades. As cidades congregam e deflagram os impulsos criativos da humanidade. Desde os tempos mais remotos, quando apenas uma fração minúscula dos seres humanos vivia em cidades, elas foram os lugares que geraram a maior parte da arte, religião, cultura, do comércio e da tecnologia da humanidade. [...] Ao longo dos cinco a sete milênios em que os homens vêm criando cidades, eles já o fizeram de incontáveis formas. [...] Acredita-se que as pegadas urbanas permanentes mais antigas estejam na Mesopotâmia, a terra entre os rios Tigre e Eufrates. Dessas raízes brotou uma infinidade de outras metrópoles sucessivas que representam as experiências fundadoras da herança urbana ocidental - incluindo Ur, Ágade, Babilônia, Nínive, Mênfis, Knossos e Tito. (KOTKIN, 2012, p.13-23-24)

Assim, também, opina Leonardo Benevolo, em História da cidade, ao considerar o assentamento e o desenvolvimento da cidade com a evolução dos meios de subsistência, com a troca dos excedentes agrícolas. Ouçamos Benevolo:

[...] a cidade permanece uma criação histórica particular, ela não existiu sempre, mas teve início num dado momento da evolução social [...]. [...] Há cerca de 5000 anos, nas planícies aluviais do Oriente Próximo, algumas aldeias se transformaram em cidades; os produtores de alimento são persuadidos ou obrigados a produzir um excedente a fim de manter uma população de especialistas: artesãos, mercadores, guerreiros e sacerdotes, que residem num estabelecimento mais complexo, a cidade [...]. A cidade [...] nasce da aldeia, mas não é apenas uma aldeia que cresceu. Ela se forma, como pudemos ver, quando as indústrias e os serviços já não são executados pelas pessoas que cultivam a terra, mas 
Em meio às trilhas do Rio de Janeiro e de Trieste com a

Lírica urbana de Reynaldo Valinho Alvarez e Umberto Saba

Delia Cambeiro

por outras que não têm esta obrigação [...]. (BENEVOLO, 2015, pp.910-23) (Grifos nossos)

Segundo Benevolo, a cidade produziu e agregou toda uma gama de especialistas em vários ramos profissionais. Recorremos interdisciplinarmente à História, ao darmos a palavra ao medievalista Jacques Le Goff, que nos aponta, também em Os intelectuais da Idade Média um "estabelecimento ainda mais complexo", como sugere Benevolo, mas na cidade medieval. Tal reflexão dialoga com as orientações de Le Goff, pois, só em uma cidade complexa Paris - teria presença no papel de berço congregador de intelectuais no séc. XII. O historiador francês cita, como figura marcante de intelectual da época, Pedro Abelardo, filósofo dialético e teólogo cristão, pai da escolástica e idealizador do conceitualismo:

No princípio foram as cidades. O intelectual da Idade Média - no Ocidente - nasce com elas. É com seu desenvolvimento, [...] que ele aparece, como um dos homens de ofício que se instalam nas cidades [...]. Só é possível encontrá-lo no século XII. É evidente que a cidade medieval não surge nessa época [...] como um cogumelo. Alguns historiadores veem-na constituída [..] no século XI, no X, [...] talvez no IX. (LE GOFF, 1984, pp.11-12)

Saímos agora da orientação de Le Goff, a respeito da cidade como campo de especialistas, no caso, da intelectualidade na Idade Média e da lembrança de Pedro Abelardo, para retomarmos as teorias da cidade, que nos alertam para o fato de a evolução da urbe materializar a história da humanidade com sua cultura. Acrescentamos, porém, à visão histórica de evolução, uma consideração estética, encontrada em História da arte como história da cidade, de Giulio Carlo Argan, ex-prefeito de Roma, a nos sugerir tratar-se a urbe de um espaço com destino propulsor da arte:

Como atividade ligada desde as mais remotas origens [...] à burguesia, a arte aparece como uma atitude tipicamente urbana. E não apenas inerente mas constitutiva da cidade, que, de fato, foi considerada durante muito tempo [...] a obra de arte por antonomásia [...]. Admirando os mirabilia urbis, tomava-se consciência dos valores históricos que os momentos representavam e significavam plasticamente. Contudo, seu verdadeiro significado consistia no fato de que estavam ali [...] uma história feita de espaço ou ambiente concreto da vida. Não apenas 
lembravam as res gestae do passado, mas significavam os atos da vida cotidiana da comunidade urbana [...]. [...] E é [a cidade] obra da arte ou, mais propriamente, das artes, ou seja, das técnicas diferenciadas mas coordenadas, que constituem a cultura da cidade.(ARGAN, 2014, pp.43108) (Grifos do autor)

Seja a comunidade urbana do Rio de Janeiro ou a de Trieste, nosso objetivo é justamente esquadrinhar a cidade, captar "os atos da vida da comunidade urbana", na lírica dos citados poetas. A cidade como matéria literária nos convida a percorrer, metaforicamente, o movimento das ruas, os rastros de sentimentos, memórias e vivências do homem citadino, suas angústias, medos, felicidades. Buscamos, enfim, sentir os passos introspectivos de um Eu poético que, certamente, hão de nos conduzir do mundo exterior das calçadas, vielas e praças, até ao interior das casas e dos edifícios, no desejo de captarem-se pulsar e batimentos das experiências de cunho coletivo e individual. Assim pensamos, por sugestão de nossa leitura de Argan, que nos estende as dimensões pulsantes do espaço urbano:

Também são espaço urbano os ambientes das casas particulares; e o
retábulo sobre o altar da igreja, a decoração do quarto de dormir ou da
sala de jantar até o tipo de roupa e de adornos com que as pessoas
andam, representam seu papel na dimensão cênica da cidade.
Também são espaço urbano, e não menos visual por serem mnemônico-
imaginárias, as extensões da influência da cidade além dos seus limites: a
zona rural, de onde chegam os mantimentos para o mercado da praça, e
onde o citadino tem suas casas e suas propriedades, os bosques onde ele
vai caçar, o lago ou os rios onde vai pescar; e onde os religiosos têm seus
mosteiros e os militares suas guarnições.(ARGAN, 2014,p.43) (grifos
nossos)

Muito se propaga a respeito do fluxo desagregador e angustiado de homens sós, emparedados na multidão, desumanizados "na dimensão cênica da cidade", sem dúvida uma geografia objeto de inúmeras idealizações registradas no imaginário coletivo, seja como espaço de refúgio, uma utopia um desejado locus amoenus; seja espaço de perigo, uma distopia para seus habitantes - um temido locus horrendus. Determinadas questões propostas há alguns séculos e eternizadas em obras universais, de teor filosófico, continuam paradigmas de reflexão prontos a nos orientar. De tais obras escolhemos 
primeiramente a República de Platão, à qual sempre apelamos, e nela apontamos a busca do filósofo em saber se em uma cidade “[...] _ Pode haver maior mal que a discórdia e a desagregação, que faz com que a cidade seja muitas ao invés de uma só? E pode haver maior bem do que o laço da unidade?" (PLATÃO, sd, p.26). Voltamos nossa atenção para Aristóteles, que, n'A politica, assim se expressa, para questionar "[...] o que é uma cidade?" - lembrando-nos, em termos, concepções sugeridas em Benevolo e anteriormente citadas, quanto ao crescimento da urbe:

\begin{abstract}
Até agora não se chegou a um acordo sobre esse ponto. [...] Sabemos que toda cidade é uma espécie de associação, e que associação se forma almejando algum bem, pois o homem trabalha somente para o que ele considera um bem. [...] No entanto, é visível que a cidade, à medida que se forma e se torma mais una, deixará de ser cidade; porque naturalmente cidade é multidão. A cidade se forma logo que se compõe de uma multidão suficiente para ter todas as comodidades da vida [...]. O natural da cidade é bastar-se a si própria. (ARISTÓTELES, 2007, pp.13-38-7521)
\end{abstract}

Nos trechos anteriores, os dois filósofos gregos nos impelem a indagações que nos ajudarão a formular certas questões sobre a lírica urbana de Valinho e de Saba. Tais indagações marcam a poesia destes dois líricos e nos levam, ao longo do ensaio, a tentar perceber: se as cidades do Rio de Janeiro e Trieste são muitas ou se são unas; se elas passam pelo mal da discórdia e da desagregação ou se estamos frente a uma associação objetivando ao bem; se a multidão-cidade comporta, verdadeiramente, só comodidades para o homem nela reunido em sociedade.

A pesquisa com relação ao mundo citadino cresceu bastante ao longo dos séculos, mas a existência de cidades nos chegaram ainda pelos escritos bíblicos e pela tradição religiosa. Conhecemos, por exemplo, Enoque fundada por Caim, que batizou a cidade com o nome de seu filho; Jericó, Mesopotâmia, Ur, Sodoma, Gomorra, Babilônia; e ainda nomeamos as cidades pólos energéticos do mundo: Jerusalém e Roma. E temos as cidades literárias: Cidade de Deus, de Agostinho de Hipona (354-430); Cidade virtuosa, do 
filósofo Al-Farabi (872-950 aproximadamente); Utopia, de Thomas Morus (1478-1535); Cidade do sol, de Tommaso Campanella (1568-1639); Icária, de Etienne Cabet (1758-1856). Não podemos deixar de mencionar que os Falanstérios, de Charles Fourier (1772-1837), foram experiências que em sociedade vingaram por pouco tempo, com tentativas no século XIX ocorridas na França e nos Estados Unidos. É preciso também lembrarmos de Canudos - fundada por Antônio Vicente Mendes Maciel (1830-1897), o Conselheiro - que seria, no Brasil, o Sião bendito, onde “[...] os rios eram de leite e as barrancas de cuzcuz de milho; onde poderiam viver felizes para sempre" (CUNHA,1993, p.149).

Os séculos XIX e XX assistiram às transformações urbanas de grandes centros, entre elas, a mais comentada é a efetuada em Paris, que se alargou em grandes avenidas, sob a iniciativa de Georges Eugène Haussmann, antecipando a metrópole que hoje conhecemos, já com algumas outras transformações. Tal renovação sacrificaria logradouros revividos e eternizados por Charles Baudelaire, em As flores do mal. Veremos que, quanto ao Rio de Janeiro, o poeta carioca lamenta a derrubada e os novos desenhos de várias áreas urbanas ocorridos na sua cidade, em mais de uma época, áreas estas revividas em nostálgicos poemas. O poeta triestino nos faz ouvir a voz de um Eu saudoso, que nos fala provocado por um olhar melancólico lançado à cidade. Já nos poemas do poeta carioca apreendemos que a troca humana

ficou estrangulada em inexplicável solidão, apesar da correria das grandes e pequenas ruas ou travessas, das imensas avenidas, das gentes nos trens e nas gares do metrô, nos shoppings, em bares e restaurantes: esse inconcebível silêncio humano desaba com a força de ritmos, sons, rimas nos poemas de Valinho. Associada à violência, à inquietação, a cidade se tornou privilegiado objeto de interrogação para os diversos campos do saber que se perguntem a respeito do ser humano em sociedade e, com isso, a cidade ganhou considerável campo de estudos na modernidade. (CAMBEIRO, 2016, pp.149-150)

Antes de procedermos, finalmente, à leitura de alguns poemas da lírica urbana de Valinho e de Saba, retomamos para registrar que as cidades e seus 
assentamentos permaceram conservados por documentos históricos e por mitos de origem. Sucede, no entanto, que, desde os tempos bíblicos, a cidade ficou gravada também em alguns dos 150 poemas líricos do livro dos Salmos, do rei Davi. É interessante sublinhar que, segundo mistérios da tradição, ele os compunha ouvindo a voz do vento transportador das vozes dos antepassados de sua antiguidade cultural: ouvido por Davi, o vento poético nos deixou todas essas 150 maravilhas para a humanidade. E iniciamos, com o salmo 72, a escuta daquele vento decodificado por Davi e aqui já reconhecemos a inseparável parelha homem-cidade: “[...] que floresçam como relva na terra fértil as pessoas na cidade"; no de número 137, esboça-se um canto de uma cidade de exílio: "Às margens dos rios da Babilônia, nos sentávamos e chorávamos, lembrando de Tsión (ou Sion)", neste salmo, ouvimos o entoar lírico de Luiz Vaz de Camões; no salmo 87 lemos: "Ah, maravilhas são contadas a Teu respeito, cidade de Deus".

Confirmamos a importância e beleza dos Salmos para, a seguir, abrirmos a segunda parte, com breve relato biográfico sobre Valinho e Saba, seguidos de alguns poemas dos autores em tela, com nossa leitura crítica.

\section{Em Valinho e Saba um lírico registro de suas cidades}

As origens de Trieste, não é difícil de se imaginar, são bem antigas. De seu remoto passado, ressaltamos primeiramente uma lenda ligando-a ao herói grego Jasão, que, em busca do velocino de ouro, desembarcou com os Argonautas em seu solo. Em complemento histórico à descoberta mítica, assinalamos que Trieste passou por transformações políticas capazes de fazer da cidade de Saba um importante centro econômico e cultural do então Império Austro-húngaro. Muito ainda teríamos a comentar, porém, por nossa proposta ser de cunho literário e não de discussão histórica, abreviamos os dados a respeito dessa cidade do Adriático e apenas acrescentamos que, 
somente em 1954, a cidade foi definitivamente restituída à Itália. Mas falar de Trieste nos impele a falar de seu filho maior: Umberto Saba.

Umberto Saba nasceu em Trieste - ainda sob domínio austro-húngaro que ganhou do poeta foro de matéria literária e cuja Voz lírica nos desvela um delicado esboço de memórias e reminiscências. Muito se lê sobre os anos de sua infância, fortemente marcados, pois o pai, que se convertera ao judaísmo e se casou com a mãe de Saba, abandonou-a antes do filho nascer. O rastro doloroso ficou eternizado num soneto em que o sentimento do filho está pulsante - "Mio padre è stato per me l'assassino/ fino ai vent'anni che l'ho conosciuto // Allora ho visto ch'egli era un bambino,/ e che il dono ch'io ho da lui l'ho avuto" - e sintetizado no último verso - "Eran due razze in antica tenzone".Comenta-se, ainda, sobre sua forte relação com a mulher que ajudou a criá-lo.

Já adulto, em 1938, com a promulgação da lei fascista antissemita, refugiou-se, primeiramente em Paris, depois em Roma e Firenze, onde sempre trocava de endereço, auxiliado por amigos e, em especial, pelo poeta Eugenio Montale. Usou em certo momento o pseudônimo Giuseppe Carimandrei. Em 1945 voltou a Trieste e retomou atividades na sua "Libreria antica e moderna". Elencamos os seguintes títulos de suas obras: Prose, Figure e canti, além do romance incompleto Ernesto, publicado postumamente. Em Canzoniere ficaram reunidas poesias compostas em vários momentos, razão pela qual seria inúmeras vezes revisto e aumentado, e nele se abrigaram seus sempre lembrados escritos e poemas.

Antes de comentarmos sobre o Rio de Janeiro, vamos focalizar o carioca Reynaldo Valinho Alvarez, filho de imigrantes galegos e um poeta de obra trilíngue (português, espanhol e galego); autor de mais de 20 livros de poesia nestes idiomas, alguns traduzidos em francês, inglês, italiano, espanhol, sueco, macedônio, persa, corso, galego e publicados no Brasil e no exterior. Foi premiado muitas vezes no Brasil, em Portugal, Espanha, Itália - com o prêmio 
Ca Maiore - e México; tem livros publicados no Brasil, em Portugal, na Espanha, na Itália, na Suécia e no Canadá. Entre as entidades que lhe conferiram prêmios, está a Academia Brasileira de Letras. Dentre suas inúmeras obras citamos apenas $O$ sol nas entranhas, A faca pelo fio, Lavradio, Das rias ao mar oceano, El aullido y los perros, El ultimo dia, Canto em si e outros cantos. Valinho é por nós considerado o nome maior da poesia contemporânea brasileira e também da Cidade de São Sebastião do Rio de Janeiro.

A cidade já viu a data de sua fundação confirmada em $1^{\circ}$ de março em vez de 20 de janeiro; São Sebastião é, para uns, uma deferência ao rei de Portugal e, para outros, homenagem ao dia do padroeiro; dados históricos ainda dão-nos conta da fundação da cidade ter derivado da estratégia dos portugueses contra os franceses, interessados em fincar os marcos da França Antártica no litoral carioca. Dúvidas quanto ao assunto e dados históricos podem, talvez, provocar continuados questionamentos, às vezes labirínticos e intermináveis. Certeza indiscutível é de que uma voz de arte maior e riqueza estética a falar do Rio de Janeiro pertence a Valinho.

Antes mesmo de colocarmos em diálogo nossos autores e concentrar o estudo da cidade lírica, já podemos afirmar que, entre Saba e Valinho, revelouse um elo comum capaz de nos provocar a leitura comparada de alguns de seus poemas. Tal estudo nos forneceu instumento capaz de nos orientar no que diz respeito a uma linguagem literária bastante desvinculada de tendências da primeira metade do fulgurante século XX. Saba e Valinho apresentam-se independentes das correntes herméticas, vanguardistas, futuristas, todas inovadoras e voltadas às novas descobertas de formas e temas. Em certos trechos de seus próprios escritos críticos, tanto em Valinho como em Saba, estão vários acenos à construção poética não obrigatoriamente sujeita às injunções do novo. Isto não quer dizer que o lírico carioca, não tenha exercitado pressupostos das citadas tendências, por exemplo, em "As núvens" e em "A máquina" - que aqui apenas assinalamos por limite de espaço - e 
estão inseridos em $A$ faca pelo fio: Poemas reunidos. Valinho assim nos fala sobre seu fazer poético, em entrevista à Revista Poesia Viva:

[...] Pode-se fazer poesia espontânea e ingênua, como se faz pintura naïf ou música popular, em oposição à pintura de técnica elaborada ou à música erudita. A língua também tem o registro coloquial e a norma culta. Para fazer poesia no padrão culto, é necessário ler os grandes poetas e estudar não só as regras da poética mas também as normas do idioma em que se escreve e ainda muito mais, ao longo da vida. Tudo depende do tipo de poesia que se deseja escrever e do nível de exigência requerido. [...] A criatividade que irrompe como "dom" é apenas a centelha que deflagra o incêndio. Se a matéria atingida pela centelha não for altamente combustível, o fogo logo se apaga. Os dois elementos devem caminhar juntos, num casamento perfeito: o dom e a capacidade técnica de quem o recebe. [...] Para ser bom experimentador, é preciso ter um ponto de partida, que é a tradição e um amplo conhecimento do que já se escreveu e do que se está escrevendo no âmbito da poesia. Toda inovação e toda renovação partem de algo que já existe. "No princípio era o Verbo". Não o caos ou o nada. Pode-se melhorar, mas não reinventar a roda. (ALVAREZ, )

Herdamos, também, de Saba, os seguintes planos de orientação, quanto às suas tendências, em "Quello che resta da fare ai poeti", publicado em La Voce, em 1911: "Ai poeti resta da fare la poesia onesta". Em carta enviada a Scipio Slavater, Saba sustenta com fibra, o seguinte: "L'articolo che le mando Quello che resta da fare ai poeti - è l'esposizione di un metodo di lavoro e di un programma di vita, oltre i quali non vedo per la poesia alcuna speranza di salvezza. L'ò (sic) scritto con passione, come vera prima lettera d'amore" (LAVAGETTO, 1981, p.181). Aqui já pressentimos uma forma, tal qual em Valinho, de um manifesto poético sabiano, a ser ratificado em "Amai”, poema constante de Mediterranee, coletânea incluída em Canzoniere, nos versos "Amai trite parole che non uno/osava. M'incantò la rima fiore// amore, // la più antica difficile al mondo [...] (LAVAGETTO, 1981, p.514).

Mas, por que "poesia onesta"? Porque considerava ser poesia honesta aquela oriunda do saber manifestar a verdade profunda e comum dos homens, por meio de uma forma poética aparentemente simples - "fiore" e "amore" mas que comunique conceitos universais. Compreendemos, a partir da leitura 
de "Quello che resta da fare ai poeti", que a palavra de Saba pretendesse vibrar na intenção de criar-se uma poesia original e profunda, sem que o poeta incluísse elementos supérfluos, pesantes, que serviriam para enganar a si próprio e ao leitor. Por isto, Saba critica explicitamente os poetas "opportunisti che disprezzarono la loro alta femminilità per esaltare la virilità abbietta di conquistatori di mercati e di imperi", aqui, particularmente, sua voz se dirige à figura de Gabriele D’Annunzio. Ao emblemático poeta do Decadentismo italiano - cujo estetismo e modo de vida provocaram inúmeras censuras quanto a seu exagerado e ruidoso comportamento com objetivo de glória - Saba oporia Alessandro Manzoni, poeta honesto, porque não criara com a "avidità di battimani”, mas por amor à arte investida de absoluto.

Sem nos esquecermos de que Valinho ousou o novo em certos poemas, deduzimos, a partir dos argumentos anteriores, haver um fio de união entre Saba e Valinho e que em nossos poetas ficam as experiências urbanas de um Eu lírico ligado, em maioria, ao recurso da forma simples, em versos de linha tradicional, a que já aludimos, abrigando o quotidiano de suas cidades, da vida dos habitantes, a nos transmitir o sentido de universalidade e de absoluto. De raízes atadas à tradição são, portanto, esses dois importantíssimos poetas de dicção humana a manifestarem a vida que os circunda, em especial, as cenas do homem comum de Trieste e do Rio de Janeiro. E assim o fazem com o desejo tanto de gravar, liricamente, o vai-vém de seres a se cruzarem na cidade, como o de projetar e de delinear um perfil feito com um tanto de espanto e de compreensão, no que toca aos traços de gentes anônimas em pleno bulício da urbe. Após a sintética leitura comparada dos traços que identificam os poetas assinalados, continuamos nosso ensaio no rastro da manifestação literária da cidade reynaldiana rumo a $O$ sol nas entranhas, inserido em $A$ faca pelo fio, no qual se apresenta um triste cenário da miséria humana citadina, no "poema Visão do Éden na mira do tresoitão", em que os homens se amedrontam na intimidadora força de uma arma. Sublinhamos no poema 
uma forma mais "ousada", pois os versos se iniciam em minúsculas, estão deslocados, são de métrica diversa e desprovidos de rima. Aqui Valinho se utiliza de tais recursos, para dar sugestão de movimento e transformação dos logradouros aliados ao desafio da arma. No corpo dessa nostálgica lembrança poetizada, eternizaram-se conhecidos estabelecimentos situados em ruas do centro do Rio de Janeiro, ameaçados pela arma que espreita. De fato,

[q]uem não conhecera os pontos da cidade e nomes eternizados nesta poesia - lojas, livrarias, sebos, ruas, escritores, igrejas, antigos morros e cidadãos conhecidos - poderá saborear o movimento cultural da cidade do Rio de Janeiro nesses versos. Se de tais referências algumas já não existem, a mira do revólver, entretanto, permanece na cidade. No poema, coexistem memória doce da cidade com realidade amarga da ameaça. (CAMBEIRO, 2016, p.152)

A seguir, o poema:

procuro um retalho do que vi ser em lojas empoeiradas há um resto de sangue ainda quente na sobrevivência desses velhos

envidraçados

balcões

$[\ldots]$

república do líbano luís de camões regente feijó

ali a cedofeita a menor sapataria do rio e a que mais caro vende ali na buenos aires garcia coutinho ltda. trocou os couros pelos plásticos e acabou morrendo sem plástica nem nada

o bar éden tinha um proprietário oliveira que vinha cumprimentar meu avô pressurosamente

as missas rezavam-se no santíssimo sacramento os sinos reboando sobre a avenida passos e a praça tiradentes

na igreja da lampadosa machado foi sacristão que coisa interessante imaginem que morava no morro da providência ou era do livramento vejam quanta história e ainda tem colombo só não existem mais os sebos da são josé e veja só o lima barreto na briguiet a eneida com o carlos ribeiro na livraria são josé e olha só que pena acabaram com todo o lado da quaresma

meu Deus que cidade alencarina machadiana barretiana tão marques rebelo \&rodrigueseana

vá passando o dinheiro que isto aqui é um assalto (ALVAREZ, 1999, p.211) 
Nos versos de "praia das virtudes", pertencente a Lavradio, "também composto nos moldes do poema anterior, um Rio de Janeiro redesenhado em seu litoral, com locais agora já desaparecidos, mas outra vez cartografados, em moldes de uma cidade antiga (CAMBEIRO, 2016, p.157). Assinalamos rimas nos segundos e quartos versos sem pontuação e com minúsculas:

\author{
o bordado dos dias \\ traz à tona \\ o mar submerso \\ em obscura zona \\ encerrada em barrentos \\ ataúdes \\ dorme a praia aterrada \\ das virtudes \\ onde crianças \\ descobriam conchas \\ dormem agora \\ vãs lembranças tronchas \\ dorme seu sono \\ sob as pedras rudes \\ a rejeitada praia \\ das virtudes (ALVAREZ, 2004, p. 45)
}

No segmento 24, de Noite sobre dia, constante de Lavradio - no movimento dos versos rimados "fardo/tardo/dardo/bardo", deslocados e de iniciais minúsculas - a cidade é goela que engole e devora, sem dó, a poesia do bardo citadino sem ter a quem se dirigir: o poeta, no verso deslocado, aparece como um fardo, um peso, sem mais lugar na cidade; relegado e sem função na urbe, ele "[...] recolhe do chão as árias mortas". Ouçamos seu lamento:

a cidade te engole

como a um fardo

carregas a ilusão de que a transportas

é tola a íntima espera que confortas

como para animar o passo tardo

já cruza o ar o invisível dardo

que muros atravessa e fura portas 
Em meio às trilhas do Rio de Janeiro e de Trieste com a

Lírica urbana de Reynaldo Valinho Alvarez e Umberto Saba

Delia Cambeiro

cala teu canto ó citadino bardo

e recolhe do chão as árias mortas

(ALVAREZ, 2004, p.70)

Em meio à vasta criação reynaldiana, é preciso ressaltar o livro Canto em si, construído com aguçada técnica criativa e por tratar-se de obra emblemática na poesia nacional e internacional. Canto em si, que recebeu o Prêmio Fernando Chinaglia em 1977, foi publicado em 1979 e reeditado em 2000, na forma de uma coletânea incluindo duas outras obras: Canto raso e O solitário gesto de viver. Consideramos Canto em si uma das mais criativas experiências formais acontecidas modernamente no Brasil e acrescentamos que, depois de Valinho, outros seguiram sua direção criadora. Todos os poemas são construídos em 6 estrofes, cada uma com um número crescente de versos: a primeira, em dísticos; a segunda, em tercetos; a terceira, em quartetos, e assim por diante, até chegar à sexta estrofe com heptassílabos.

De Canto em si, destacamos o segmento 13, uma nova "Canção do exílio" reynaldiana, a ouvir e a cantar o gorjeio de pássaros, os ruídos e a fumaça das máquinas, em meio às aturdidas gentes. Desta "Canção do exílio" às avessas, saltam a humanização dos pássaros e a animalização dos humanos, que gorjeiam na calçada, não nas gaiolas, soltos e endurecidos pelos enganos da metrópole, pelo barulho das máquinas, pelos descaminhos da "urbe doente". Escutemos o canto do Eu perdido entre as chagas das ruas:

As aves que gorjeiam na calçada não cantam como as aves do vizinho.

Nas áreas de serviço, entre gaiolas há troca de atenções, os bichos comem, prisioneiros do estômago viciado.

Não se luta e, se há grito, a primazia

é que se exige, não o elementar

e sofrido direito de comer

que inflama os livres pássaros da rua. 
Em janelas, varandas, coberturas, nas áreas de serviço, nas garagens, há pássaros urbanos acalmados, às vezes esquecidos do cantar devido pelo alpiste recebido.

Os outros, que estão livres, se aturdiram com o grito metálico das máquinas e soltam poucas vezes o seu canto entre muros, fumaças e canteiros de obras que se escancaram como chagas, na cirurgia imposta à urbe doente.

Os pássaros não cantam como anteontem talvez porque os ouvidos já não ouvem do jeito com que ouviam até ontem e guardam cada canto com a história que todo canto teve e que a memória ainda insiste em reter, mesmo que o canto não se distinga mais, entre área e rua. (ALVAREZ, 2000, p.39)

Vamos agora ao poema "Robinson Crusoé no meio da tempestade", incluído em As portas (c)erradas da percepção, quarta parte de $O$ sol nas entranhas, clara confissão de uma alma sozinha, convulsionada em sua tempestade interior. Nos entremeios, ouvimos um náufrago da cidade em monólogo reflexivo com seu mundo-ilha quotidiano, emparedado dentro da sala de trabalho. Essa ilha fica, na imaginação poética do Eu lírico, no alto de um prédio no centro da cidade do Rio de Janeiro, entre Candelária e Ipanema. Vamos a esse Robinson Crusoé do asfalto - poema conciliador de versos livres sem pontuação e iniciais minúsculas - outro magnífico poema de profundo teor confessional, quase epistolar, vindo de um Eu a nos segredar angústias, ânsias, naufrágios de um cidadão urbano:

aqui de onde estou escuto as buzinas do trânsito congestionado chove devagar nesta noite de quinta-feira são dezoito horas e vinte e cinco minutos e apesar de as janelas estarem fechadas neste décimo oitavo andar as buzinas chegam como urros desesperados até mim $[\ldots]$ chamarei o motorista da companhia e seguirei solitário de qualquer modo estarei ilhado no meio do tráfego 
Em meio às trilhas do Rio de Janeiro e de Trieste com a

Lírica urbana de Reynaldo Valinho Alvarez e Umberto Saba

Delia Cambeiro

estarei ilhado dentro de mim

estarei ilhado

não sou mais que uma ilha sem comunicação com o continente

$[\ldots]$

estou largado aqui

perdido nesta ilha de caos e solidão

perplexo para sempre

assistindo à perda corrosiva da memória

$[\cdots]$

aqui onde me escondo não me liberto de mim

e caio prisioneiro de meu profundo terror

nesta noite de chuva quero um conhaque e não o tenho

o que tenho é um estômago vazio

esperando pela longa viagem para ipanema

pela ginástica corretiva antes do banho

pelo banho antes do jantar

pelo jantar antes de tudo

estou condenado a esperar que a chuva passe e o tráfego melhore

estou condenado à solidão desta ilha

enquanto a máquina se agita num voo de gaivota

(ALVAREZ, 1982, pp.60-61)

A recorrente atmosfera de um mundo absurdo concretizado na urbe doente, impressa em grande parte da poesia de Valinho, está no texto anterior e se expande no poema "A grande corrida de touros", quando a Voz lírica se debate presa no picadeiro, no abatedouro da cidade. Ainda no mesmo fluxo entre Ipanema e Candelária - microcosmo de mentiras, distópica via insuportável e inexorável cadafalso para o Sujeito lírico. Insiste, nestes versos, a metáfora do mundo cruel, do locus horrendus, em versos livres:

levantarei amanhã com as costas doloridas

mal-humorado e indisposto

para enfrentar o trabalho

sim para enfrentar

porque terei de pegá-lo como se pega um touro pelos chifres

e por que tem de ser assim e não de outra maneira?

sinto dores lombares a coluna me incomoda

por que me incomoda a coluna se não me curvo

ou é porque não me curvo que me incomoda a coluna?

estou farto de fazer sempre o mesmo papel

mas não sei fazer outro papel

que não o papel que querem que eu faça

estou cansado de mentiras

mas não sei se suportarei a verdade

quem poderá suportá-la 
Em meio às trilhas do Rio de Janeiro e de Trieste com a

Lírica urbana de Reynaldo Valinho Alvarez e Umberto Saba

Delia Cambeiro

nesta manhã de trânsito congestionado

entre ipanema e a candelária? (CAMBEIRO, 2016, pp. 221-222)

E o que dizer da poesia de Umberto Saba? O que ela manifesta liricamente sobre o mundo - a cidade de Trieste? Já adiantamos ser sua poesia o encontro de, em certa medida, um locus amoenus desencadeador, por meio da Voz poética, de melancólicas reminiscências, de memórias e de convivências de antanho. Comecemos, então, o estudo de alguma poesia do famoso triestino e, para tanto, selecionamos belíssimos textos bastante conhecidos, como por exemplo, "Trieste", "Città vecchia", "Trevie” e "Il borgo".

Percebemos em "Trieste" um Eu que examina, acompanha com o olhar a cidade, em alguns pontos ela é "popolosa”, em outros, vão-se rareando as pessoas. Mas em "Città vecchia", a Voz poética entra e se imiscui no coração e no burburinho das ruas do bairro, na tentativa de sentir a essência dos habitantes, na apreciação e acompanhamento do desfile de gente. Elas andam, movem-se por ruas e calçadas, estão em quarteirões mal afamados, são de aspectos marcantes. De uma subida, "da un'erta" e de um cantinho, "da um cantuccio", nós leitores vemos o bairro junto com o Eu sentado em um muro, provável limite do espaço. Em oposição à observação estática de "Trieste”, a de "Città Vecchia" tem seu reconhecimento lírico em vielas. Para o Sujeito lírico de "Trieste", são muitos os contrastes e silêncios a percorrer imóvel, sozinho, guiado pelo movimento interno, quando reconstroi a cidade da memória a vazar reminiscências de uma vida meditada e tímida: "vita pensosa e schiva".

Em "Città vecchia" - em meio a antíteses como "scontrosa grazia" rimam-se outros paroxismos, tais quais: "lupanare/mare; detrito/infinito; friggitore/amore; dolore/Signore", palavras pertencentes ao vocabulário quotidiano; as banais, um tanto vulgares e rudes, como "pozzanghera", "bega", "lupanare”, "bestemmia”, "prostituta”, “marinaio", ganham 
inconfundível sonância no poema, dão frescor à linguagem poética construída por Saba. A seguir, “Trieste” e "Città vecchia”, de versos livres e sem rima:

\section{Trieste}

Ho traversatta tutta la città.

Poi ho salita un'erta, popolosa in principio, in là deserta, chiusa da un muricciolo:

un cantuccio in cui solo siedo; e mi pare che dove esso termina termini la città.

Trieste ha una scontrosa grazia. Se piace, è come un ragazzaccio aspro e vorace, con gli occhi azzurri e mani troppo grandi per regalare un fiore; come un amore con gelosia.

Da quest'erta ogni chiesa, ogni sua via scopro, se mena all'ingombrata spiaggia, o alla collina cui, sui la sassosa cima, una casa, l'ultima, s'aggrappa. Intorno circola ad ogni cosa un'aria strana, un'aria tormentoso, l'aria natia.

La mia città che in ogni parte è viva, ha il cantuccio a me fatto, alla mia vita pensosa e schiva.(LAVAGETTO, 1981, p.196)

\section{Città vecchia}

Spesso, per ritornare alla mia casa prendo un'oscura via di città vecchia.

Giallo in qualche pozzanghera si specchia qualche fanale, e affollata è la strada.

Qui tra la gente che viene che va dall'osteria alla casa o al lupanare, dove son merci ed uomini il detritto di un gran porto di mare, io ritrovo, passando, l'infinito nell'umiltà.

Qui prostituta e marinaio, il vecchio che bestemmia, la femmina che bega, il dragone che siede alla bottega del friggitore,

la tumultuante giovanne impazzita 
Em meio às trilhas do Rio de Janeiro e de Trieste com a

Lírica urbana de Reynaldo Valinho Alvarez e Umberto Saba

Delia Cambeiro

d'amore

sono tutte creature della vita

e del dolore;

s'aggita in esse, come in me, il Signore.

Qui degli umili sento in compagnia

il mio pensiero farsi

più puro dove più turpe è la vita. (LAVAGETTO, 1981, p.197)

Em "Tre vie" e "Il borgo", sem dúvida, está um mundo exterior - nas ruas de Trieste - que, em contrapartida, impele o Eu flâneur a seu interior profundo, assim, de novo, como nos demais poemas, tenta (re)descobrir sua realidade e a dos outros triestinos. A sugestão de passeio aguça o olhar desse passeador desejoso de rever antigos caminhos da cidade guardados e agora vivenciados liricamente. Diríamos ser uma espécie de fidelidade amorosa por Trieste e seus habitantes que o leva a retomar antigos lugares, quase mágicos, em momentos de nostalgia. Se em "Tre vie" as ruas trazem o tempo de uma "si grande gioia", um "dolce tempo d'infanzia", ao flâneur, que, agora, nelas se espelha narcisicamente - no sentido de interiorizar-se para o autoconhecimento - em "Il borgo" delineia-se a sugestiva vontade de sair de si mesmo e partilhar-se, viver com/como os outros homens. Dores do físico e da alma encontram para a nostálgica Voz poética - diríamos em toda poesia sobre Trieste - o alívio e a redescoberta de antigos sentimentos com a possibilidade de volta no tempo. De algum modo, a dor se apazígua no anulamento de si, no "immedesimarsi”: metamorfose capaz de fusão, de união com os homens e, assim, a Voz de "Il borgo" se faz universal cumprindo o destino da literatura. Com linguagem simples, porém carregada de significado a ser eternamente explorado, estão construídos os dois seguintes poemas, de versos livres, com pontuação e ecos de alguma rima.

Primeiramente, "Tre vie":

C’è a Trieste una via dove mi specchio nei lunghi giorni di chiusa tristezza; si chiama Via del Lazzaretto Vecchio.

Tra case come ospizi antiche uguali, 
ha una nota, una sola, d'allegrezza; il mare in fondo alle sue laterali. Odorata di droghe e di catrame dai magazzini desolati a fronte, fa commercio di reti, di cordame per le navi: un negozio ha per insegna una bandiera; nell'interno, volte contro il passante, che raro le degna d'uno sguardo, coi volti esangui e proni sui colori di tutte le nazioni, le lavoranti scontano la pena della vita: innocenti prigioniere cuciono tetre le allegre bandiere.

A Trieste ove son tristezze molte, e bellezze di cielo e di contrada, c'è un'erta che si chiama Via del Monte. Incomincia con una sinagoga, e termina ad un chiostro; a mezza strada ha una cappella; indi la nera foga della vita scoprire puoi da un prato, e il mare con le navi e il promontorio, e la folla e le tende del mercato.

Pure, a fianco dell'erta, è un camposanto abbandonato, ove nessun mortorio entra, non si sotterra più, per quanto io mi ricordi: il vecchio cimitero degli ebrei, così caro al mio pensiero, se vi penso ai miei vecchi, dopo tanto penare e mercatare, là sepolti, simili tutti d'animo e di volti.

Via del Monte è la via dei santi affetti, ma la via della gioia e dell'amore è sempre Via Domenico Rossetti. Questa verde contrada suburbana, che perde dì per dì del suo colore, che è sempre più città, meno campagna, serba il fascino ancora dei suoi belli anni, delle sue prime ville, sperse, dei suoi radi filari d'alberelli.

Chi la passeggia in queste ultime sere d'estate, quando tutte sono aperte le finestre, e ciascuna è un belvedere, dove agucchiando o leggendo si aspetta, pensa che forse qui la sua diletta rifiorirebbe all'antico piacere di vivere, di amare lui, lui solo; 
e a più rosea salute il suo figliolo.

E, a seguir, "Il borgo", quando sublinhamos a repetição de "tutti", ao correr do poema, a configurar o desejo de immedesimarsi:

Fu nelle vie di questo

Borgo che nuova cosa m'avvenne.

Fu come un vano sospiro

il desiderio improvviso d'uscire

di me stesso, di vivere la vita

di tutti,

d'essere come tutti

gli uomini di tutti

$i$ giorni.

Non ebbi io mai sì grande

gioia, né averla dalla vita spero.

Vent'anni avevo quella volta, ed ero

malato. Per le nuove

strade del Borgo il desiderio vano

come un sospiro

mi fece suo.

Dove nel dolce tempo

d'infanzia

poche vedevo sperse

arrampicate casette sul nudo

della collina,

sorgeva un Borgo fervente d'umano

lavoro. In lui la prima

volta soffersi il desiderio dolce

e vano

d'immettere la mia dentro la calda

vita di tutti,

d'essere come tutti

gli uomini di tutti

$i$ giorni.

La fede avere

di tutti, dire

parole, fare

cose che poi ciascuno intende, e sono, come il vino ed il pane,

come i bimbi e le donne,

valori

di tutti. Ma un cantuccio,

ahimé, lasciavo al desiderio, azzurro

spiraglio,

per contemplarmi da quello, godere

l'alta gioia ottenuta

di non esser più io, 
Em meio às trilhas do Rio de Janeiro e de Trieste com a

Lírica urbana de Reynaldo Valinho Alvarez e Umberto Saba

Delia Cambeiro

d'essere questo soltanto: fra gli uomini

un uomo.

Nato d'oscure

vicende,

poco fu il desiderio, appena un breve

sospiro. Lo ritrovo

- eco perduta

di giovinezza - per le vie del Borgo

mutate

più che mutato non sia io. Sui muri

dell'alte case,

sugli uomini e i lavori, su ogni cosa,

è sceso il velo che avvolge le cose

finite.

La chiesa è ancora

gialla, se il prato

che la circonda è meno verde. Il mare,

che scorgo al basso, ha un solo bastimento,

enorme,

che, fermo, piega da un parte. Forme,

colori,

vita onde nacque il mio sospiro dolce

e vile, un mondo

finito. Forme,

colori,

altri ho creati, rimanendo io stesso,

solo con il mio duro

patire. E morte

m'aspetta.

Ritorneranno,

o a questo

Borgo, o sia a un altro come questo, $i$ giorni

del fiore. Un altro

rivivrà la mia vita,

che in un travaglio estremo

di giovinezza, avrà per egli chiesto,

sperato,

d'immettere la sua dentro la vita

di tutti,

d'essere come tutti

gli appariranno gli uomini di un giorno

d'allora.

Com estes últimos poemas, abrimos para o capítulo final da Conclusão.

\section{3. À guisa de conclusão}


Chegamos ao final do trabalho e retomamos para assinalar que na lírica urbana reynaldiana se manifesta a desconcertante realidade de uma rua, uma praça, um bairro, enfim, o desalinho humano representado na cidade do Rio de Janeiro, cujos habitantes transitam indiferenciados, em meio a uma inquieta multidão. Representadas estão aglomerações a se deslocarem e a se acotovelarem na cidade apinhada, porém, a multidão transita sem se falar, sem afetividade possível na urbe congestionada, que, tragicamente, mostra a fratura de um mundo cuja troca humana ficou estrangulada em solidão, medo e ameaças. Tais desacertos tocam o sensível olho lírico de um Eu em desarmonia e, como resultado, emergem dos desenhos poéticos reynaldianos ecos de simbólica lástima pelo sofrimento humano.

Já em Saba, não pudemos levantar sinais de divórcio entre o homem e a cidade, pois este é o espaço de um colóquio íntimo entre o homem e a cidade. Nos poemas aqui comentados, a errância da memória, os passeios de mútuo encontro - Eu e Trieste - sinalizam a busca obsessiva do encontro e do encontrar-se. Nos poemas de Saba, ressoa uma velada e pulsante felicidade de infância, a dor humana é meio de investigação do flâneur desejoso de, justamente, ultrapassar a dor das reminiscências, entretanto, cidade provoca no Sujeito lírico um certo conforto moral, não remete a medo ou a ameaças. Apesar da diferença cronológica entre as obras dos dois autores, diversa da cidade de Valinho é a dos poemas de Saba, sem dúvida, uma Trieste algumas vezes movimentada, viva, rumorosa, sugerindo-nos comunicação entre habitantes. Às vezes, Trieste se torna quieta, fechada para o bulício de seus habitantes, quando o interior do Eu busca alento na paisagem. Na lírica de Saba a cidade não se configura como espaço de infortúnio, ela proporciona alento; já nas vias expressas da cidade de Valinho delineiam-se a inexorável dissolução das relações humanas e um vaso incandescente de violência.

Para finalizar, segundo o que assinalamos em outra parte do trabalho, consideramos o carioca e o triestino como poetas periféricos, pois, de fato, 
Em meio às trilhas do Rio de Janeiro e de Trieste com a

Lírica urbana de Reynaldo Valinho Alvarez e Umberto Saba

Delia Cambeiro

firmaram-se em tal classificação devido à independência criada no processo de elaboração de suas poéticas, aprimoradas no equilíbrio entre permanência/convivência do clássico e do contemporâneo.

\section{Referências bibliográficas}

ALVAREZ, Reynaldo Valinho. O sol nas entranhas. São Paulo: Editora Três, 1982.

- A faca pelo fio. Poemas reunidos. Rio de Janeiro: Fundação Biblioteca Nacional/Imago Editora, 1999.

. Canto em si. São Paulo: Barcarola Editora, 2000.

. Lavradio. Rio de Janeiro: Myrrha, 2004.

. Das rias ao mar oceano. Rio de Janeiro: Ágora da Ilha, 2000.

. O solitário gesto de viver. Rio de Janeiro: Tempo Brasileiro; Brasília: INL, 1980.

. El aullido y los perros. In: . El último día. Rio de Janeiro, Contraste, 2009.

ARGAN, Giulio Carlo. A história da arte como história da cidade. São Paulo: Martins Fontes, 2014.

ARISTOTELES. A política. Trad. Nestor Silveira Chaves. São Paul: Martins Fontes, 1998.

BENEVOLO, Leonardo. História da cidade. 4.ed. Trad. Sílvia Mazza. São Paulo: Perspectiva, 2009.

CAMBEIRO, Delia. A cidade e o olhar do poeta. Ensaio sobre a lírica urbana de Reynaldo Valinho Alvarez. Rio de Janeiro: Contraste Editora, 2016.

CUNHA, Euclides da.Os Sertões. Rio de Janeiro: Francisco Alves, 1993.

KOTKIN, Joel. A cidade: uma história global. Trad. Rafael Mantovani. Rio de Janeiro: Editora Objetiva, 2012.

LAVAGETTO, Mario (a cura). Per conoscere Saba. Milano, Mondadori, 1981. 
LE GOFF, Jacques. Os intelectuais na Idade Média. 2. ed. Trad. Margarida Sérvulo Correia. Lisboa: Gradiva, 1984.

MUSCETTA, Carlo (a cura). Antologia del "Canzoniere". Torino: Giulio Einaudi Editore, 1972.

PLATÃO. República. Rio de Janeiro: Tecnoprint, sd.

POESIA VIVA. Entrevista com Reynaldo Valinho Alvarez. Rio de Janeiro: Editora UAP, ano 12, nº 12, maio 2007.

SABA, Umberto. Mediterráneas.Trad. Esther Morillas. Valencia: Editorial PreTextos, 1991. Edición bilíngue.

SALMOS.Vitor Fridlin e Jairo Fridlin (Tradução e transliteração). 2 ed. São Paulo: Sêfer, 2001.

TODOROV, Tzvetan. A literatura em perigo. Trad. Caio Meira. Rio de Janeiro: DIFEL, 2009. 


\section{In mezzo ai sentieri di Rio de Janeiro e di Trieste con la lirica urbana di Reynaldo Valinho Alvarez e Umberto Saba ${ }^{2}$}

RIASSUNTO: La città nella lirica urbana è stato l'oggetto delle nostre ricerche da qualche tempo e la stiamo sviluppando in articoli, prefazioni, oltre alle pubblicazione e alle presentazioni di libri con la stessa tematica. In questo breve saggio, proponiamo due poeti che ci si mostrano speciali per quanto riguarda la letteratura come manifestazione dei desideri, delle angosce e delle meraviglie dell'essere umano abitante dell'Urbe. Con le esperienze estetiche di Valinhos e di Saba, vogliamo far riflettere in che maniera essi catturano le sfumature della vita di città; intendiamo anche indagare sull'intensità lirica delle loro poesie nel difficile cammino dell'uomo cittadino, simbolicamente osservato sia in esilio di sofferenza, in un terribile locus horrendus oppure in un regno di felicità, in un sognato locus amoenus. A tali interrogativeutilizzeremo alcuni poemi degli autori proposti per lo studio e dei titoli teorici sulla città.

Parole-Chiave: Teorie della città. Lirica urbana. ReynaldoValinho Alvarez. Umberto Saba. Rio de Janeiro. Trieste.

ABSTRACT: The city in the urban lyric has been the object of our research for some time, being developed in articles and also in published books on that theme. In this brief article, we discuss two poets that stand out in their approach to literature as a manifestation of thelonging, distress and wonder of the human being that inhabit the urbe. With the aesthetical experience of Valinho and Saba, we wish to reflect upon the way both capture the nuances of city life, and also question the lyrical intensity of their poetry, the hardships of the city man, symbolically observed in an exile of suffering - a dreafullocus horrendus or in a reign of happiness - a locus amoenus. For the purposes of this questioning, we will work with some poems by the proposed authors ofstudies and theoretical titles on the city.

Keywords: City Theories. Urban Lyric. Reynaldo Valinho Alvarez. Umberto Saba. Rio de Janeiro; Trieste.

\footnotetext{
2 Versione di Alcebiades Arêas e Edvaldo Sampaio Belizário.

${ }^{3}$ Post-Dottorato in Letteratura Comparata presso l'Università A Coruña (UDC) Spagna. Prof.ssa Ordinaria presso l'UERJ.
} 


\section{All'incontro delle teorie sulle città}

Il carioca ReynaldoValinho Alvarez (1931) e il triestino Umberto Saba Poli, conosciuto come il poeta Umberto Saba (1883-1957), sono dei nomi che consolidano, con raro vigore, la lirica urbana sulle loro città di nascita. Sia la città di Rio de Janeiro che la città di Trieste, malgrado la distanza geografica, hanno delle strutture comuni, costruite con un alto grado di bellezza e di dominio della forma.

Prima di svolgere il nostro lavoro su questi illuminati poeti, faremo un sintetico orientamento teorico riguardante il tema città, con lo scopo di iniziare il nostro percorso investigativo che ci porterà all'incontro di un lirico e malinconico Io flâneur, svelato tra le righe dei poemi scelti per il nostro studio. Con questo obiettivo, alterneremo alla lirica urbana qualche concetto teorico sulla città che ci aiuteranno nella lettura dei poemi urbani, senza compromettere però il privilegio della poesia, bersaglio innegabile di questo saggio.

Decidiamo per il dialogo tra letteratura e scienza, cioè, fra testo immaginativo e teorie della città, grazie alla suggestiva parola di TzvetanTodorov, che, nel suo libro La letteratura in pericolo (2007, pp. 28-2931), valuta il contributo di tale "conversazione" interdisciplinare. Il maestro bulgaro, deceduto da poco, il 7 febbraio 2017, al far riferimento alle possibili voci aggiuntive del testo letterario, ci insegna a delimitare però il campo dell'interferenza e dell'importanza, poiché, a suo avviso, "... in nessun caso lo studio di questi mezzi deve sostituirsi a quello del significato, che è il fine, [...] il significato stesso di questa ricerca". Per trattarsi evidentemente di una battuta complementare e argomentativa, egli afferma che "[...] nessuna si riferisce a quel che dicono le opere in sé, il loro senso, il mondo che evocano". In effetto, non si riferiscono specificamente all'arte poetica, ma, qui 
l'applichiamo, perché crediamo che in maniera significativa complementino, argomentino e dicano sul tema proposto.

Prima di entrare nel merito della questione riguardante i poemi di Valinho e di Saba, rivolgiamo la nostra attenzione al tema proposto e affermiamo che riflettere sulla città non è un compito facile, malgrado ci siano tanti discorsi teorici già registrati in diverse lingue e in parecchie traduzioni in portoghese. Il fenomeno città, bisogna sottolineare, non è una preoccupazione esclusiva del XX e/o XXI secolo, neppure furono questi periodi che misero in evidenza l'osservazione e la storia di una geografia così eccitante. Le radici della città nascono nei più remoti sentieri del tempo, come appunto ci orienta Joel Kotkin, ne La città: una storia globale. Così egli ci chiarisce quanto all'universalità dell'esperienza dell'uomo nella città:

L'evoluzione della città materializza la storia dell'umanità. [...] . La più grande creazione dell'umanità fu le sue città. Le città congregano e deflagrano gli impulsi creativi dell'umanità. Sin dai tempi più remoti, quando solo una frazione minuscola degli esseri umani viveva nelle città, esse furono i luoghi che generarono la maggior parte dell'arte, religione, cultura, del commercio e della tecnologia dell'umanità. [...] Nel corso dei cinque a sette millenni in cui gli uomini costruiscono città, essi lo fecero già in innumerevoli forme. [...] $\mathrm{Si}$ credono che le orme urbane permanenti più antiche siano nella Mesopotamia, la terra che si trova tra $i$ fiumi Tigri ed Eufrate. Da queste radici nacque un'infinità di altre metropoli successive che rappresentano le esperienze fondatrici dell'eredità urbana occidentale - ivi comprese Ur, Agade, Babilonia, Ninive, Menfi, Cnosso e Tito.

Anche Leonardo Benevolo in Storia della città la pensa così quando considera l'insediamento e lo sviluppo della città con l'evoluzione dei mezzi di sussistenza, con lo scambio delle eccedenze agricole:

[...] la città resta una creazione storica particolare, non è sempre esistita, ma è cominciata a un certo momento dell'evoluzione sociale [...]. [..] Circa 5000 anni fa, nelle pianure alluvionali del Vicino Oriente, alcuni villaggi si trasformano in città; i produttori di cibo sono persuasi o costretti a produrre un'eccedenza per mantenere una popolazione di specialisti: artigiani, mercanti, guerrieri e sacerdoti, che risiedono in un 
Em meio às trilhas do Rio de Janeiro e de Trieste com a

Lírica urbana de Reynaldo Valinho Alvarez e Umberto Saba

Delia Cambeiro

insediamento più complesso, la città [...]. La città [...] nasce dal villaggio ma non è solo un villaggio ingrandito. Si forma, come abbiamo visto, quando le industrie e i servizi non sono più esercitati dalle persone che coltivano la terra, ma da altre che non hanno quest'obbligo [...]. (BENEVOLO, 2015, pp. 9-10-23) (Il grassetto è nostro)

Per Benevolo, la città produsse e aggregò una grande quantità di specialisti in diverse branche professionali. Ricorriamo interdisciplinarmente alla Storia dando la parola al medievalista Jacques Le Goff, che ci indica anche, neGli intellettuali nel Medioevo, un "insediamento ancora più complesso", come suggerisce Benevolo, ma nella città medievale. Questa riflessione dialoga con gli orientamenti di Le Goff, poiché solo una città complessa come Parigi - avrebbe presenza nel ruolo di culla aggregativa di intellettuali nel XII secolo. Lo storico francese cita, come la prima grande figura di intellettuale del tempo, Pietro Abelardo, filosofo dialettico e teologo cristiano, padre della scolastica e ideatore del concettualismo.

$\mathrm{Al}$ principio vi furono le città. In Occidente l'intellettuale del Medioevo nell'Occidente - nasce con esse, appare nel periodo della loro espansione $[\ldots]$ come uno di quegli artieri che si stabiliscono nei centri urbani $[\ldots]$. Solo nel XII secolo se ne afferma chiaramente la figura. Certo, la città medioevale non si schiude in Occidente a quest'epoca [...] come un fungo. Vi sono storici, anzi, che la veggono già del tutto costituita nell'XI secolo, nel X, [...] forse dal IX. (LE GOFF, 1984, pp. 11-12)

Lasciamo ora l'orientamento di Le Goff riguardo la città come campo degli esperti, cioè degli intellettuali del Medioevo e del ricordo di Pietro Abelardo, e ritorniamo alle teorie della città, le quali ci avvertono del fatto che lo sviluppo dell'urbe materializzi la storia dell'umanità con la cultura. Aggiungiamo, però, alla visione storica di evoluzione, una considerazione estetica, trovata nella Storia dell'arte come storia della città di Giulio Carlo Argan, ex sindaco di Roma, che suggerisce di essere l'urbe uno spazio con destino propulsivo dell'arte.

Come attivitàcollegata fin dallepiù remote origini[...] allaborghesia, l'arteappare come un'attivitàtipicamente urbana. E non soltanto inerente 
Em meio às trilhas do Rio de Janeiro e de Trieste com a

Lírica urbana de Reynaldo Valinho Alvarez e Umberto Saba

Delia Cambeiro

ma costitutiva della città, che infatti è stata considerata per molto [...] l'opera d'arte per antonomasia [...]. Ammirando i mirabiliaurbis, si prendeva coscienza dei valori storici che i monumenti plasticamente rappresentavano e significavano; ma il loro vero significato consisteva nel fatto che erano là [...] una storia fatta spazio ed ambiente concreto della vita. Non soltanto rammentavano e celebravano le res gestaedel passato, ma magnificavano gli atti della vita quotidiana della comunità cittadina [...]. Ed è [la città] opera d'arte o, più propriamente, delle arti, cioè delle tecniche differenziate ma coordinate, che costituiscono la cultura della città. (ARGAN, 2014, pp. 43-108) (I corsivi sono dell'autore)

Sia la comunità urbana di Rio de Janeiro, sia quella di Trieste, il nostro obiettivo è proprio quello di scrutare la città, captare "gli atti della vita della comunità urbana", nella lirica dei suddetti poeti. La città come materia letteraria ci invita a percorrere, metaforicamente, gli andirivieni delle strade, le scie di sentimenti, ricordi ed esperienze dell'uomo cittadino, le sue angosce, timori, felicità. Cerchiamo, quindi, di sentire i passaggi introspettivi di un Io poetico che, sicuramente, ci condurranno dal mondo esterno dei marciapiedi, delle viuzze e delle piazze, fino all'interno delle case e degli edifici, con il desiderio che si siano captati il pulsare e i battiti delle esperienze di carattere collettivo e individuale. Così pensiamo, stimolati dalla lettura di Argan che ci estende le dimensioni pulsanti dello spazio urbano:

Sono spazio urbano anche gli ambienti delle case private; e la pala sull'altare della chiesa, l'arredo della camera da letto o da pranzo fino all'abbigliamento e all'ornamento con cui le persone si muovono, recitando la loro parte nella dimensione scenica della città. Sono spazio urbano, e non meno visivo per essere mnemonico-immaginario, le estensioni dell'influenza della città oltre la sua cinta: il contado di dove giungono le derrate al mercato della piazza, e dove il cittadino ha le sue ville e i suoi poderi, $i$ boschi dove va a caccia, il lago o i fiumi dove va a pescare; e dove i religiosi hanno i loro monasteri e i militari le loro guarnigioni. (ARGAN, 2014, p. 43) (Il grassetto è nostro)

Spesso si diffonde rispetto al flusso disgregatore e angosciante degli uomini soli, imprigionati nella folla, disumanizzati "nella dimensione scenica della città" , senz'altro una geografia oggetto di innumerevoli idealizzazioni registrate nell'immaginario collettivo, sia come spazio di rifugio, un'utopia - un 
desiderato locus amoenus - sia come spazio di pericolo, una distopia per gli abitanti - un temuto locus horrendus. Certe questioni proposte da qualche secolo e immortalate nelle grandi opere della letteratura universale, di contenuto filosofico, seguono come paradigmi di riflessione pronti ad orientarci. Di queste opere scegliamo dapprima la Repubblica di Platone, cui rivolgiamo sempre, e in essa indichiamo la ricerca del filosofo per sapere se in una città “[...] Ma esiste forse un male più grande per la città di quello che la fa a brani, rendendola molteplice anziché una? O un bene maggiore di quello che la lega insieme, rendendola una?" (PLATONE, sd, p. 26). Rivolgiamo la nostra attenzione ad Aristotele che, nella Politica, così si esprime per indagare "[...] cos'è una città?" - ricordandoci, in termini, accezioni suggerite da Benevolo e sopraddette, quanto alla crescita dell'urbe:

Finora non si è arrivato ad un accordo su questo punto. [...] Vediamo che ogni città è una sorta di comunità e che ogni comunità è costituita per il conseguimento di un certo bene, poiché l'uomo lavora soltanto per quello che considera un bene [...] Eppure, è evidente che man mano che la città sorge e si sviluppa, perde le sue caratteristiche; perché naturalmente la città è un'associazione di cittadini, il cui fine e la miglior vita possibile. [...]. Il naturale della città è bastarsi a sé stessa.

Nei brani precedenti, i due filosofi greci ci portano a domande che ci aiuteranno a formulare certe questioni sulla lirica urbana di Valinho e di Saba. Tali domande segnano la poesia di questi due lirici e ci portano a cercare di percepire, lungo il saggio: se le città di Rio de Janeiro e Trieste sono molteplici o se sono uniche; se subiscono il male della discordia e della disgregazione oppure se stiamo di fronte a un'associazione che mira al bene; se la folla-città ammette, effettivamente, solo comodità per gli uomini in essa raggruppati in società.

La ricerca riguardante al mondo cittadino si sviluppò molto nel corso dei secoli, ma l'esistenza delle città ci arrivò anche dagli scritti biblici e dalla tradizione religiosa. Conosciamo, per esempio, Enoch fondata da Caino, che la battezzò con il nome di suo figlio; Gerico, Mesopotamia, Ur, Sodoma, 
Gomorra, Babilonia; e nominiamo ancora le città poli energetici del mondo: Gerusalemme e Roma. E abbiamo le città letterarie: Città di Dio, di Agostino d'Ippona (354-430); Città virtuosa, del filosofo Al-Farabi (872-950 ca); Utopia di Thomas Morus (1478-1535; Città del sole, di Tommaso Campanella (15681639), Icaria di ÉtienneCabet (1772-1856). Non dimenticheremo di citare che i Falansteri di Charles Fourier (1772-1837), furono esperienze che nella società durarono poco tempo, con dei tentativi avvenuti nel XIX secolo in Francia e negli Stati Uniti. Bisogna ricordare anche Canudos - fondata da Antônio Vicente Mendes Maciel (1830-1897), detto il Consigliere - che sarebbe, in Brasile, il Sion benedetto, dove "[...] i fiumi erano di latte e i barranchi di couscous di mais; dove potrebbero vivere felici per sempre" (CUNHA,1993, p.149).

I secoli XIX e XX assistettero alle trasformazioni urbane dei grandi centri, tra di esse, la più commentata è quella di Parigi, che si allargò in lunghi viali, sotto le iniziative di Georges Eugène Haussmann, anticipando la metropoli che oggi conosciamo, ma in cui ci sono già state altre modifiche. Tale rinnovamento sacrificherebbe dei luoghi rivissuti e immortalati da Charles Baudelaire neI fiori del male. Vedremo che, per quel che riguarda il Rio de Janeiro, il poeta carioca si rammarica per la demolizione e per i nuovi disegni di parecchie aree urbane avvenuti nella città, in più di un'epoca e rivissute in nostalgici poemi. Il poeta triestino ci fa ascoltare la voce di un Io malinconico, che ci parla provocato da uno sguardo tetro lanciato sulla città. Nei poemi del poeta carioca, però, notiamo che lo scambio umano

rimase strangolato in inspiegabile solitudine, malgrado il ritmo frenetico delle grandi e piccole vie o traverse, degli immensi viali, delle persone nei treni e nelle stazioni della metro, nei centri commerciali, nei bar e nei ristoranti: questo inconcepibile silenzio umano crolla con la forza dei ritmi, suoni, rime nei poemi di Valinho. Associata alla violenza, all'inquietudine, la città diventò oggetto privilegiato di interrogazione per i diversi campi del sapere che si domandano sull'essere umano in società e, così, la città ottenne un considerevole campo di studi nell'attualità. (CAMBEIRO, 2016, pp.149-150) 
Prima di cominciare finalmente la lettura dei poemi della lirica urbana di Valinho e di Saba, riprendiamo il discorso per registrare che le città e i loro insediamenti rimasero conservati da documenti storici e dai miti di origine. Sta però di fatto che dai tempi biblici la città rimase anche registrata in alcuni dei 150 poemi lirici del libro dei Salmi del re Davide. È interessante sottolineare che, secondo i misteri della tradizione, egli li componeva ascoltando la voce del vento trasportatore delle voci degli antenati della sua antichità culturale: udito da Davide, il vento poetico ci lasciò tutte queste 150 meraviglie per l'umanità. E iniziamo l'ascolto di quel vento decifrato da Davide, con il salmo 72, e qui riconosciamo già l'inseparabile binomio uomocittà: "[...] gli abitanti delle città fioriranno come l'erba della terra"; nel salmo 137, viene abbozzato un canto di una città d'esilio: "Là, presso i fiumi di Babilonia, sedevamo e piangevamo ricordandoci di Sion", in questo salmo sentiamo il canto lirico di LuísVaz de Camões; nel salmo 87, leggiamo: "Cose gloriose sono dette di te, o città di Dio".

Confermiamo l'importanza e la bellezza dei Salmi perché, di seguito, possiamo aprire la seconda parte, con un breve profilo biografico di Valinho e Saba, accompagnata dalla nostra lettura critica su qualche poema dei due autori in questione.

\section{In Valinho e Saba un lirico registro delle loro città}

Le origini di Trieste, non è difficile immaginare, sono assai antiche. Dal suo passato remoto, distacchiamo in primo luogo una leggenda, collegandola all'eroe greco Giasone che, in cerca del vello d'oro, sbarcò con i suoi Argonauti nel suolo triestino. Come complemento storico alla scoperta mitica, segnaliamo che Trieste subì delle trasformazioni politiche capaci di fare la città di Saba diventare un importante centro economico e culturale dell'Impero Austro-Ungarico d'allora. Avremmo ancora molto da commentare, ma, 
essendo la nostra proposta di carattere letterario piuttosto che una discussione storica, abbiamo limitato le informazioni relative a questa città dell'Adriatico, aggiungendo, peraltro, che solo nel 1954 essa fu definitivamente restituita all'Italia. Comunque, soffermarsi su Trieste ci spinge a parlare del suo più illustre figlio, il poeta Umberto Saba.

Umberto Saba nacque a Trieste - ancora sotto il dominio dell'Impero austroungarico - che ebbe dal poeta foro di materia letteraria e la cui Voce lirica ci rivela un delicato abbozzo di memorie e reminiscenze. Si legge spesso sugli anni della sua infanzia, fortemente segnati, poiché suo padre, dopo essersi convertito al giudaismo e aver sposato la madre di Saba, la abbandonò prima che egli fosse nato. La traccia dolorosa rimase immortalata in un sonetto in cui il sentimento del figlio è pulsante - "Mio padre è stato per me "l'assassino"/ fino ai vent'anni che l'ho conosciuto // Allora ho visto ch'egli era un bambino, / e che il dono ch'io ho da lui l'ho avuto" - e sintetizzata nel verso finale - "Eran due razze in antica tenzone". Si commenta ancora il suo forte legame con la donna che aiutò ad allevarlo.

Nel 1938, ormai diventato adulto, con la promulgazione delle leggi razziali antisemite, si rifugiò prima a Parigi, poi a Roma e a Firenze, dove cambiava sempre indirizzo aiutato da amici e, specialmente dal poeta E. Montale. Usò per un certo periodo lo pseudonimo Giuseppe Carimandrei. Nel 1945 tornò a Trieste e riprese le attività nella sua "Libreria antica e moderna". Elenchiamo i seguenti titoli delle sue opere: Prose, Figure e canti, oltre il romanzo incompiuto Ernesto, pubblicato postumo. Per riunite poesie composte in momenti diversi, Il Canzoniere sarebbe stato rivisto e ampliato innumerevoli volte e in esso furono racchiusi i suoi memorabili scritti e poemi.

Prima di parlare della città di Rio de Janeiro, metteremo a fuoco il carioca ReynaldoValinho Alvarez, figlio di immigrati galleghi e un poeta di opera trilingue (portoghese, spagnolo e gallego); autore di oltre venti libri di poesie in portoghese, spagnolo e gallego, alcuni dei quali tradotti in francese, 
inglese, italiano, spagnolo, svedese, macedone, persiano, corso, gallego e pubblicati in Brasile e all'estero. Fu molte volte premiato in Brasile, Portogallo, Spagna, Italia - con il premio Camaiore - e in Messico; ha dei libri pubblicati in Brasile, Portogallo, Spagna, Italia, Svezia e Canada. Tra gli enti che gli conferirono dei premi, c'è l'Accademia Brasiliana di Lettere. Tra le sue innumerevoli opere citiamo solo $O$ sol nasentranhas, A faca pelo fio, Lavradio, Dasriasao mar oceano, El aullido y losperros, El ultimo dia, Canto emsi e outroscantos. Valinho viene considerato da noi il più grande nome della poesia contemporanea brasiliana e anche della città di San Sebastiano di Rio de Janeiro.

La città aveva già visto la data della sua fondazione il primo marzo invece del 20 gennaio; San Sebastiano risulta, per alcuni, una specie di deferenza al re di Portogallo e, per altri, un omaggio al giorno del santo patrono della città; dati storici ci danno ancora conto della fondazione della città provocata dalle azioni dei portoghesi contro $i$ francesi interessati a stabilire la Francia Antartica nella zona costiera di Rio de Janeiro. Dubbi sull'argomento e dati storici possono, forse, provocare continue riflessioni, alle volte, labirintiche e interminabili. Comunque, è certo ed indiscutibile che un'espressione d'arte maggiore e di ricchezza estetica, che parla di Rio de Janeiro, appartiene a Valinho.

Ancor prima di mettere in dialogo i nostri autori e di concentrarci sullo studio della città lirica, possiamo già affermare che, tra Saba e Valinho, si rivelò un legame comune capace di spingerci a fare una lettura comparata di alcuni dei loro poemi. Questo studio ci fornì uno strumento in grado di orientarci per quanto riguarda un linguaggio letterario abbastanza svincolato dalle tendenze della prima metà del folgorante XX secolo. Saba e Valinho si mostrano indipendenti dalle correnti ermetiche, avanguardiste, futuristiche, tutte innovatrici e rivolte alle nuove scoperte di forme e temi. In alcune parti dei loro propri scritti critici, sia nell'opera di Valinho che in quella di Saba, ci 
sono parecchi accenni alla costruzione poetica non obbligatoriamente soggetta alle imposizioni del nuovo. Ciò non vuol dire che il poeta carioca non abbia utilizzato dei principi delle summenzionate tendenze, come per esempio, nelle poesie "Asnúvens" e "A máquina" - che qui non possiamo fare altro che menzionarne i titoli per una questione di spazio - e che appartengono alla raccolta A faca pelo fio: poemasreunidos. Così ci parla Valinho del suo fare poetico nell'intervista alla Rivista Poesia Viva:

[...] Si può fare poesia spontanea e ingenua, come si realizza pittura naif o musica popolare, in opposizione alla tecnica pittorica elaborata o alla musica erudita. La lingua ha anche il registro colloquiale e la norma colta. Per fare poesia nel registro alto della lingua, ci vuole leggere i grandi poeti e studiare non solo le regole della poetica ma anche le norme dell'idioma in cui si scrive e ancora molto di più nel corso della vita. Tutto dipende dal tipo di poesia che si vuole scrivere e dal livello di esigenza richiesto. [...]La creatività che erutta come "dono" è solo la scintilla che fa scoppiare l'incendio. Se il materiale raggiunto dalla scintilla non è fortemente infiammabile, il fuoco si spegne presto. I due elementi devono andare di pari passo, in un'unione perfetta: il dono e la capacità tecnica di chi lo riceve. [...] Per essere un buono sperimentalista bisogna avere un punto di partenza, che è la tradizione e un'ampia conoscenza di quello che si scrisse e di quello che si sta scrivendo nell'ambito della poesia. Ogni innovazione e ogni rinnovamento partono da qualcosa di già esistente. "In principio era il Verbo". Non il caos o il nulla. Si può migliorare, ma non si può reinventare la ruota. (ALVAREZ)

Da Saba, ereditammo anche i seguenti piani di orientamento, quanto alle sue tendenze, in "Quello che resta da fare ai poeti”, pubblicato ne La Voce, nel 1911: "Ai poeti resta da fare la poesia onesta". In una lettera inviata a Scipio Slavater, Saba sostiene con risolutezza quanto segue: 'L'articolo che le mando - Quello che resta da fare ai poeti - è l'esposizione di un metodo di lavoro e di un programma di vita, oltre i quali non vedo per la poesia alcuna speranza di salvezza. L'ò (sic) scritto con passione, come vera prima lettera d'amore" (LAVAGETTO, 1981, p.181). Qui presagiamo già una forma, come quella trovata in Valinho, di un manifesto poetico sabiano, ad essere convalidato nei versi del poema "Amai", che fa parte dell'opera Mediterranee, inclusa nella raccolta Canzoniere:"Amai trite parole che non uno/osava. M'incantò la rima 
fiore// amore, // la più antica difficile al mondo [...] (LAVAGETTO, 1981, p.514).

Ma, perché "poesia onesta"? Perché onesta era quella poesia proveniente dal saper manifestare la verità profonda e comune degli uomini, tramite una forma poetica apparentemente semplice - "fiore" e "amore" - ma che comunicasse concetti universali. Comprendiamo, a partire dalla lettura di "Quello che resta da fare ai poeti", che la parola di Saba intendesse vibrare nel tentativo di creare una poesia originale e profonda, senza che il poeta vi includesse degli elementi superflui, pesanti, che servirebbero per ingannare sé stesso e il lettore. Perciò Saba critica esplicitamente i poeti "opportunisti che disprezzarono la loro alta femminilità per esaltare la virilità abbietta di conquistatori di mercati e di imperi", qui, particolarmente, la sua voce si rivolge alla figura di Gabriele D'Annunzio. All'emblematico poeta del Decadentismo italiano - il cui estetismo e il modo di vita provocarono innumerevoli censure quanto al suo esagerato e turbolento atteggiamento con lo scopo di gloriarsi - Saba contrapporrebbe Alessandro Manzoni, poeta onesto, perché non aveva creato con la "avidità di battimani", ma per amore dell'arte investita d'assoluto.

Senza dimenticarci che Valinho osò innovare in certi poemi, deduciamo, a partire dagli argomenti precedenti, che c'è un filo comune tra Saba e Valinho e che nei nostri poeti restano le esperienze urbane di un Io lirico legato, in maggioranza, al ricorso della forma semplice, in versi di linea tradizionale, di cui parlammo precedentemente, preservando il quotidiano delle loro città, della vita degli abitanti, e trasmettendoci il significato di universalità e di assoluto. Con le radici attaccate alla tradizione, questi due importantissimi poeti di dizione umana manifestano la vita che li circonda, in special modo, le scene dell'uomo comune di Trieste e di Rio de Janeiro. E lo fanno così sia con il desiderio di registrare liricamente l'andirivieni di persone che s'incrociano nella città, sia per proiettare e delineare un profilo fatto con un 
po' di sgomento e di comprensione, per quel che riguarda la traccia di persone anonime in pieno trambusto dell'urbe. Dopo la sintetica lettura comparata delle tracce che identificano i poeti segnalati, continuiamo il nostro saggio nella scia della manifestazione letteraria della città reynaldiana verso $O$ sol nasentranhas, inserito nella raccolta $A$ faca pelo fio, in cui si presenta un triste scenario della miseria umana cittadina, nel poema "Visão do Édenna mira do tresoitão", in cui gli uomini s'impauriscono di fronte alla forza intimidatoria di un'arma. Sottolineiamo nel poema una forma più "ardita", poiché i versi iniziano con una lettera minuscola, sono spostati, sono di metrica diversa e privi di rima. Qui Valinho si avvale di questi ricorsi per suggerire movimento e trasformazione dei luoghi associati alla sfida dell'arma. Nel corpo di questo nostalgico ricordo poetizzato, si immortalarono noti negozi situati nelle vie del centro di Rio de Janeiro, minacciati dall'arma che sta in agguato. Difatti,

chi non conobbe i punti della città e i nomi immortalati in questa poesia negozi, librerie, librerie dell'usato, vie, scrittori, chiese, vecchie colline e cittadini conosciuti - potrà godere il movimento culturale della città di Rio de Janeiro in questi versi. Se di tali referenze alcune non esistono più, la minaccia della pistola, però, rimane nella città. Nel poema, coesiste la dolce memoria della città con l'amara realtà della minaccia.

Riportiamo qui di seguito la poesia:

procuro um retalho do que vi ser em lojas empoeiradas

há um resto de sangue ainda quente nas obrevivência desses velhos

balcões envidraçados

$[\ldots]$

república do Líbano luís de camões regente feijó

ali a cedofeita a menor sapataria do rio e a que mais caro vende ali na buenosaires Garcia Coutinho ltda. Trocou os couros pelos plásticos e acabou morrendosem plástica nem nada o baré dentinha um proprietário oliveira que vinha cumprimentar meu avô pressurosamente

as missas rezavam-se no santíssimo sacramento os sinos reboando sobre a avenida passos e a praça tiradentes

na igreja da lampadosa machado foi sacristão que coisa interessante imaginem que morava no morro da providência ou era do livramento vejam quanta história e aindatem colombo 
Em meio às trilhas do Rio de Janeiro e de Trieste com a

Lírica urbana de Reynaldo Valinho Alvarez e Umberto Saba

Delia Cambeiro

só não existem mais os sebos da são josé

e veja só o lima Barreto na briguiet

a Eneida com o Carlos ribeiro na livraria são josé

e olhas ó que pena acabaram com todo o lado da quaresma

meu Deus que cidade alencarinmachadianabarretiana

tão marquesrebelo \& rodrigueseana

vá passando o dinheiro que isto aqui é um assalto(ALVAREZ, 1999, p.211)

Nei versi della "praia das virtudes", appartenente al libro Lavradio, "composto sulla falsa riga del poema precedente, una Rio de Janeiro ridisegnata nella sua costa, con dei luoghi ormai scomparsi, ma di nuovo cartografati, modellati sulla falsariga di una città antica (CAMBEIRO, 2016, p. 157). Segnaliamo che il secondo verso fa rima col quarto e che il poema è scritto senza punteggiatura e con le lettere minuscole:

o bordado dos dias
traz à tona
o mar submerso
em obscura zona
encerrada
embarrentos
ataúdes
dorme a praiaaterrada
dasvirtudes
onde crianças
descobriam conchas
dormem agora
vãs lembranças
tronchas
dorme seu sono
sob as pedras rudes
a rejeita da praia
das virtudes(ALVAREZ, 2004, p. 45)

Nel segmento 24, della Noitesobre dia, presente nel libro Lavradio - nel movimento dei versi rimati "fardo/tardo/dardo/bardo/", spostati e con le iniziali minuscole - la città è come fauci che inghiottiscono e divorano, senza pietà, la poesia del bardo cittadino senza sapere a chi rivolgersi: il poeta, nel verso spostato, appare come un fardello, un peso, perdendo il suo posto nella 
Em meio às trilhas do Rio de Janeiro e de Trieste com a

Lírica urbana de Reynaldo Valinho Alvarez e Umberto Saba

Delia Cambeiro

vita cittadina; relegato e senza funzione nell'urbe, egli “[...] recolhe do chãoasáriasmortas". Udiamo il suo lamento:

a cidade te engole

como a um fardo

carregas a ilusão de que a transportas

é tola a íntima espera que confortas

como para animar o passo tardo

já cruza o ar o invisível dardo

que muros atravessa e fura portas

cala teu canto ó citadino bardo

e recolhe do chão a sáriasmortas (ALVAREZ, 2004, p.70)

In mezzo alla vasta creazione di Valinho, bisogna individuare il libro Canto em si, costruito con stuzzicante tecnica creativa e per trattarsi di un'opera emblematica nella poesia nazionale ed internazionale. Canto em si, che vinse il premio Fernando Chinaglia nel 1977, fu pubblicato nel 1979 e riedito nel 2000 sotto forma di raccolta comprese due altre opere: Canto raso e $O$ solitário gesto de viver. Riteniamo Canto em si una delle più creative esperienze formali avvenute modernamente in Brasile e aggiungiamo che, dopo Valinho, altri seguirono la sua direzione creativa. Tutti i poemi sono composti di sei strofe, ciascuna delle quali ha un numero crescente di versi: la prima, in distico; la seconda, in terzina; la terza, in quartina, e così via, fino ad arrivare alla sesta strofa eptastica.

Del Canto em si, evidenziamo il segmento 13, una nuova "Canção do exílio" reynaldiana, ad ascoltare e a cantare il trillo degli uccelli, i rumori e il fumo delle macchine, in mezzo alla folla intontita. In questa "Canção do exílio" a ritroso, spiccano l'umanizzazione degli uccelli e l'animalizzazione degli umani, che cinguettano sul marciapiede, fuori dalle gabbie, liberi e induriti dagli inganni della metropoli, dal rumore delle macchine, dagli stravizi della "urbe malata". Udiamo il canto dell'Io perduto tra le piaghe delle vie: 
Em meio às trilhas do Rio de Janeiro e de Trieste com a

Lírica urbana de Reynaldo Valinho Alvarez e Umberto Saba

Delia Cambeiro

As aves que gorjeiam na calçada

Nãocantam como as aves do vizinho.

Nas áreas de serviço, entre gaiolas

Há troca de atenções, os bichos comem, prisioneiros do estômago viciado.

Não se luta e, se hágrito, a primazia

é que se exige, não o elementar

e sofrido direito de comer

que inflama os livres pássaros da rua.

Em janelas, varandas, coberturas,

Nas áreas de serviço, nas garagens, há pássaros urbanos acalmados, às vezes esquecidos do cantar devido pelo alpiste recebido.

Os outros, que estão livres, se aturdiram com o grito metálico das máquinas e soltam poucas vezes o seu canto entre muros, fumaças e canteiros de obras que se escancaram como chagas, na cirurgia imposta à urbe doente.

Os pássaros não cantam como anteontem Talvez porque os ouvidos já não ouvem do jeito com que ouviam até ontem e guardam cada canto com a história que todo canto teve e que a memória ainda insiste em reter, mesmo que o canto não se distinga mais, entre área e rua. (ALVAREZ, 2000, p.39)

Vediamo adesso il poema "Robinson Crusoé no meio da tempestade", incluso nell'opera Asportas (c)erradas da percepção, la quarta parte di $O$ sol nasentranhas, una chiara confessione di un'anima solitaria, convulsa nella sua tempesta interiore. Nel frattempo, sentiamo un naufrago della città in monologo riflessivo con il suo mondo-isola quotidiano, murato nella stanza di servizio. Quest'isola si trova, nell'immaginazione poetica dell'Io lirico, in cima ad un edificio nel centro della città di Rio de Janeiro, tra Candelária e Ipanema. Andiamo a questo Robinson Crusoé dell'asfalto - poema conciliatore di versi liberi senza punteggiatura e iniziali maiuscole - un altro 
magnifico poema di profondo contenuto confessionale, quasi epistolare, venuto da un Io che sussurra le angosce, le ansie, i naufragi di un cittadino urbano.

aqui de onde estou escuto asbuzinas do trânsito congestionado

chove devagar nesta noite de quinta-feira

são dezoito horas e vinte e cinco minutos

e apesar de as janelas estaremfechadas neste décimo oitavo andar as buzinas chegam como urros desesperados até mim

$[\ldots]$

chamarei o motorista da companhia e seguirei solitário

de qualquer modo estarei ilhado no meio do tráfego

estarei ilhado dentro de mim

estarei ilhado

não sou mais que uma ilha semcomunicação com o continente

$[\ldots]$

Estou largado aqui

perdido nesta ilha de caos e solidão

perplexo para sempre

assistindo à perda corrosiva da memória

$[\ldots]$

aqui onde me escondo não me liberto de mim

e caio prisioneiro de meu profundo terror

nesta noite de chuva quero um conhaque e não o tenho

o que tenho é um estômago vazio

esperando pela longa viagem para ipanema

pela ginástica corretiva antes do banho

pelo banho antes do jantar

pelo jantar antes de tudo

estou condenado a esperar que a chuva passe e o tráfego melhore

estou condenado à solidão desta ilha

enquanto a máquina se agita num voo de gaivota

(ALVAREZ, 1982, pp.60-61)

La ricorrente atmosfera di un mondo assurdo concretizzato nell'urbe malata, descritta in gran parte nella poesia di Valinho, è presente nel testo anteriore e si espande nel poema "A grande corrida de touros", quando la Voce lirica si dibatte imprigionata nella pista, nel mattatoio della città. Ancora 
nello stesso flusso tra Ipanema e Candelária - microcosmo di menzogne, distopica via insopportabile e spietato patibolo per il Soggetto lirico. Insiste, in questi versi, la metafora del mondo crudele, del locus horrendus, in versi liberi.

Levantarei amanhã com as costas doloridas

mal-humorado e indisposto

para enfrentar o trabalho

sim para enfrentar

porque terei de pegá-lo como se pega um touro pelos chifres

e por que tem de ser assim e não de outra maneira?

Sinto dores lombares a coluna me incomoda

por que me incomoda a coluna se não me curvo

ou é porque não me curvo que me incomoda a coluna?

Estou farto de fazer sempre o mesmo papel

mas não sei faze outro papel

que não o papel que querem que eu faça

estou cansado de mentiras

mas não sei se suportarei a verdade

quem poderá suportá-la

nesta manhã de trânsito congestionado

entre ipanema e a candelária? (CAMBEIRO, 2016, pp.221-222)

E che dire della poesia di Umberto Saba? Cosa essa manifesta liricamente sul mondo - la città di Trieste? Anticipiamo già che la sua poesia in certa misura è l'incontro di un locus amoenus scatenante, tramite la Voce poetica, di malinconiche reminiscenze, di memorie e di convivenze di una volta. Cominciamo quindi lo studio di qualche poesia del famoso triestino e a tale scopo abbiamo selezionato dei bellissimi testi molti conosciuti come, per esempio, "Trieste", "Città vecchia", "Tre vie" e "Il borgo".

Notiamo in "Trieste" un Io che esamina, accompagna con lo sguardo la città, e in alcuni punti essa è "popolosa", in altri, diventano rare le persone. Ma in "Città vecchia", la Voce poetica entra e si mischia al cuore e al brusio delle vie del quartiere, al tentativo di sentire l'essenza degli abitanti, all'apprezzamento ed accompagnamento della sfilata di gente. Esse camminano, si muovono per le vie e sui marciapiedi, sono nei quartieri malfamati, sono persone dai tratti marcati. "Da un'erta" e "da un cantuccio", noi lettori vediamo il quartiere insieme all'Io seduto su un muro, probabile 
limite dello spazio. In opposizione all'osservazione statica di "Trieste" quella di "Città vecchia" ha il suo riconoscimento lirico nelle viuzze. Per il soggetto lirico di "Trieste", sono molti i contrasti e silenzi da percorrere immobile, da solo, guidato dal movimento interno, quando ricostruisce la città della memoria, facendo scorrere le reminiscenze di una vita meditata e timida: "vita pensosa e schiva”.

In "Città vecchia" - in mezzo ad antitesi come "scontrosa grazia" - fanno rima altri parossismi, come: "lupanare/mare; detrito/infinito; friggitore/amore; dolore/Signore", parole appartenenti al vocabolario quotidiano; quelle banali piuttosto volgari e rozze, come "pozzanghere", "bega", "lupanare", "bestemmia", "prostituta", "marinaio", guadagnano un'inconfondibile assonanza nel poema, danno freschezza al linguaggio poetico costruito da U. Saba. Di seguito, "Trieste" e "Città vecchia", di versi liberi e senza rima:

Trieste

Ho attraversatto tutta la città.

Poi ho salita un'erta, popolosa in principio, in là deserta, chiusa da un muricciolo: un cantuccio in cui solo siedo; e mi pare che dove esso termina termini la città.

Trieste ha una scontrosa grazia. Se piace, è come un ragazzaccio aspro e vorace, con gli occhi azzurri e mani troppo grandi per regalare un fiore;

come un amore

con gelosia.

Da quest'erta ogni chiesa, ogni sua via scopro, se mena all'ingombrata spiaggia, o alla collina cui, sui la sassosa cima, una casa, l'ultima, s'aggrappa.

Intorno

circola ad ogni cosa

un'aria strana, un'aria tormentoso, l'aria natia.

La mia città che in ogni parte è viva, ha il cantuccio a me fatto, alla mia vita 
Em meio às trilhas do Rio de Janeiro e de Trieste com a

Lírica urbana de Reynaldo Valinho Alvarez e Umberto Saba

Delia Cambeiro

pensosa e schiva. (LAVAGETTO, 1981, p.196)

\section{Città vecchia}

Spesso, per ritornare alla mia casa prendo un'oscura via di città vecchia.

Giallo in qualche pozzanghera si specchia

qualche fanale, e affollata è la strada.

Qui tra la gente che viene che va

Dall'osteria alla casa o al lupanare, dove son merci ed uomini il detrito

di un gran porto di mare,

io ritrovo, passando, $l^{\prime}$ infinito

nell'umiltà.

Qui prostituta e marinaio, il vecchio

che bestemmia, la femmina che bega,

il dragone che siede alla bottega

del friggitore,

la tumultuante giovaneimpazzita

d'amore

sono tutte creature della vita

e del dolore;

s'agitain esse, come in me, il Signore.

Qui degli umili sento in compagnia

il mio pensiero farsi

più puro dove più turpe è la via. (LAVAGETTO, 1981, p.197)

In "Tre vie" e "Il borgo", senza dubbio, vi è un mondo esterno - nelle vie di Trieste - che, peraltro, spinge l'Io flâneur al suo interiore profondo, così, di nuovo, come negli altri poemi, cerca di (ri)scoprire la sua realtà e quella degli altri triestini. L'invito ad una passeggiata aguzza lo sguardo di questo passeggiatore desideroso di rivedere antiche strade della città conservate e ora sperimentate liricamente. Diremmo che è una specie di fedeltà amorosa a Trieste e ai suoi abitanti che lo porta a riprendere vecchi posti, quasi magici, in momenti di nostalgia. Se in "Tre vie" le strade portano il tempo di una "sì grande gioia", di un "dolce tempo d'infanzia", al flâneur, che, adesso, vi si rispecchia narcisisticamente - nel senso di interiorizzarsi per l'autoconoscenza - ne "Il borgo" si delinea la suggestiva volontà di uscire da sé stesso e spartire con gli altri, vivere con e come gli altri uomini. I dolori del corpo e dell'anima 
trovano per la nostalgica Voce poetica - diremmo in tutta la poesia su Trieste sollievo e riscoperta di vecchi sentimenti con la possibilità di tornare indietro nel tempo. In ogni caso, il dolore si placa nell'annullamento di sé, nello "immedesimarsi": metamorfosi capace di fusione, di unione con gli uomini e, così, la Voce di "Il borgo" si fa universale compiendo il destino della letteratura. Con un linguaggio semplice però pieno di significato ad essere eternamente esplorato, sono costruiti i due seguenti poemi, di versi liberi, con punteggiatura ed alcuni echi di rima.

Prima di tutto, "Tre vie":

C'è a Trieste una via dove mi specchio nei lunghi giorni di chiusa tristezza; si chiama Via del Lazzaretto Vecchio. Tra case come ospizi antiche uguali, ha una nota, una sola, d'allegrezza; il mare in fondo alle sue laterali. Odorata di droghe e di catrame dai magazzini desolati a fronte, fa commercio di reti, di cordame per le navi: un negozio ha per insegna una bandiera; nell'interno, volte contro il passante, che raro le degna d'uno sguardo, coi volti esangui e proni sui colori di tutte le nazioni, le lavoranti scontano la pena della vita: innocenti prigioniere cuciono tetre le allegre bandiere.

A Trieste ove son tristezze molte, e bellezze di cielo e di contrada, c'è un'erta che si chiama Via del Monte. Incomincia con una sinagoga, e termina ad un chiostro; a mezza strada ha una cappella; indi la nera foga della vita scoprire puoi da un prato, e il mare con le navi e il promontorio, e la folla e le tende del mercato.

Pure, a fianco dell'erta, è un camposanto abbandonato, ove nessun mortorio entra, non si sotterra più, per quanto io mi ricordi: il vecchio cimitero degli ebrei, così caro al mio pensiero, se vi penso ai miei vecchi, dopo tanto 
penare e mercatare, là sepolti, simili tutti d'animo e di volti.

Via del Monte è la via dei santi affetti, ma la via della gioia e dell'amore è sempre Via Domenico Rossetti. Questa verde contrada suburbana, che perde dì per dì del suo colore, che è sempre più città, meno campagna, serba il fascino ancora dei suoi belli anni, delle sue prime ville, sperse, dei suoi radi filari d'alberelli.

Chi la passeggia in queste ultime sere d'estate, quando tutte sono aperte le finestre, e ciascuna è un belvedere, dove agucchiando o leggendo si aspetta, pensa che forse qui la sua diletta rifiorirebbe all'antico piacere di vivere, di amare lui, lui solo; e a più rosea salute il suo figliolo.

E, di seguito, "Il borgo", quando sottolineiamo la ripetizione della parola "tutti” nel corso del poema, configurando il desiderio d'immedesimarsi:

Fu nelle vie di questo

Borgo che nuova cosa

m'avvenne.

Fu come un vano

sospiro

il desiderio improvviso d'uscire

di me stesso, di vivere la vita

di tutti,

d'essere come tutti

gli uomini di tutti

$i$ giorni.

Non ebbi io mai sì grande gioia, né averla dalla vita spero.

Vent'anni avevo quella volta, ed ero malato. Per le nuove

strade del Borgo il desiderio vano

come un sospiro

mi fece suo.

Dove nel dolce tempo

d'infanzia

poche vedevo sperse

arrampicate casette sul nudo

della collina, 
sorgeva un Borgo fervente d'umano

lavoro. In lui la prima

volta soffersi il desiderio dolce

e vano

d'immettere la mia dentro la calda

vita di tutti,

d'essere come tutti

gli uomini di tutti

$i$ giorni.

La fede avere

di tutti, dire

parole, fare

cose che poi ciascuno intende, e sono,

come il vino ed il pane,

come i bimbi e le donne,

valori

di tutti. Ma un cantuccio,

ahimé, lasciavo al desiderio, azzurro

spiraglio,

per contemplarmi da quello, godere

l'alta gioia ottenuta

di non esser più io,

d'essere questo soltanto: fra gli uomini

un uomo.

Nato d'oscure

vicende,

poco fu il desiderio, appena un breve

sospiro. Lo ritrovo

- eco perduta

di giovinezza - per le vie del Borgo

mutate

più che mutato non sia io. Sui muri

dell'alte case,

sugli uomini e i lavori, su ogni cosa,

è sceso il velo che avvolge le cose

finite.

La chiesa è ancora

gialla, se il prato

che la circonda è meno verde. Il mare,

che scorgo al basso, ha un solo bastimento,

enorme,

che, fermo, piega da un parte. Forme,

colori,

vita onde nacque il mio sospiro dolce

e vile, un mondo

finito. Forme,

colori,

altri ho creati, rimanendo io stesso, solo con il mio duro

patire. E morte 
Em meio às trilhas do Rio de Janeiro e de Trieste com a

Lírica urbana de Reynaldo Valinho Alvarez e Umberto Saba

Delia Cambeiro

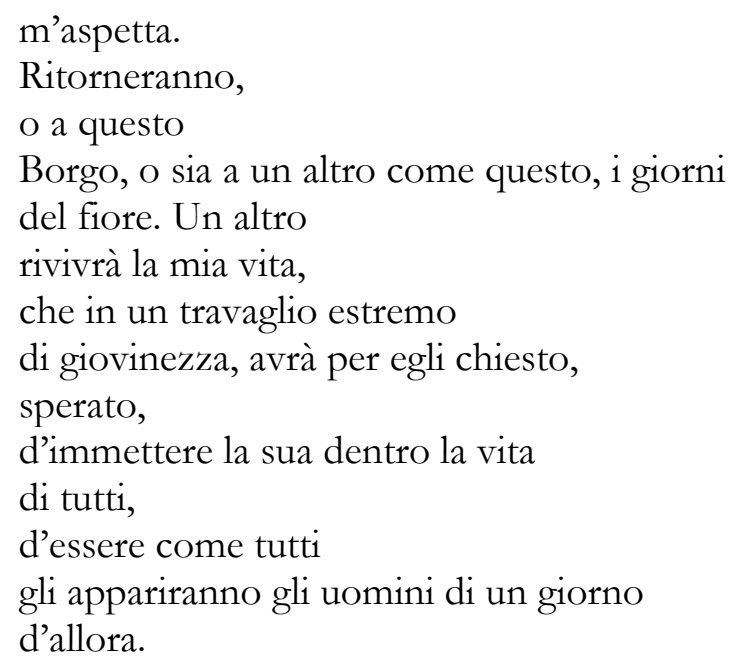

Con questi ultimi poemi giungiamo al capitolo delle nostre considerazioni finali.

\section{Conclusione}

Siamo arrivati alla fine del lavoro e riprendiamo per segnalare che nella lirica urbana di ReynaldoValinho si manifesta la sconcertante realtà di una via, di una piazza, di un quartiere, infine, il disordine umano rappresentato nella città di Rio de Janeiro, i cui abitanti transitano indifferenziati, in mezzo a una inquieta moltitudine. Rappresentati sono anche assembramenti di persone in movimento che si accalcano e si spintonano nella città affollata, però, queste persone si muovono per la città senza scambiarsi parole, senza cordialità possibile nell'urbe congestionata che, tragicamente, mostra la frattura di un mondo il cui scambio umano si ridusse alla solitudine, alla paura e alle minacce. Tali errori toccano il sensibile occhio lirico di un Io in disarmonia e, come risultato, emergono dai disegni poetici reynaldiani degli echi di simbolica commiserazione per la sofferenza umana.

In Saba però non possiamo parlare di segni di divorzio tra l'uomo e la città, poiché questo è lo spazio di un colloquio intimo tra l'uomo e la città. Nei poemi qui commentati, il divagare della memoria, le passeggiate di 
reciproco incontro - Io e Trieste - segnalano la ricerca ossessiva dell'incontro e dell'incontrarsi. Nei poemi di Saba, risuona una velata e pulsante felicità d'infanzia, il dolore umano è un mezzo di investigazione del flâneur desideroso di, giustamente, sorpassare il dolore delle reminiscenze, tuttavia, la città provoca nel Soggetto lirico un certo conforto morale, non suscita paura o minacce. Malgrado lo scarto temporale tra le opere dei due autori, diversa dalla città di Valinho è quella dei poemi di Saba, senza dubbio, una Trieste qualche volta agitata, viva, rumorosa, suggerendoci la comunicazione tra gli abitanti. Talvolta, Trieste diventa silenziosa, chiusa al brulichio degli abitanti, quando l'interno dell'Io cerca un po' di quiete nel paesaggio. Nella lirica di Saba la città non si configura come spazio di infortunio, essa fornisce quiete; nelle strade della città di Valinho si delineano l'inesorabile disfacimento dei rapporti umani e un vaso incandescente di violenza.

Per concludere, secondo quello che abbiamo segnalato precedentemente in questo articolo, consideriamo il carioca e il triestino come poeti periferici, poiché, infatti, si definirono così dovuto all'indipendenza creata nel processo di elaborazione delle loro poetiche perfezionate nell'equilibrio tra permanenza/convivenza del classico e del contemporaneo.

\section{Riferimenti Bibliografici}

ALVAREZ, ReynaldoValinho. O sol nas entranbas.São Paulo: EditoraTrês, 1982.

A faca pelo fio. Poemas reunidos. Rio de Janeiro: Fundação Biblioteca Nacional/Imago Editora, 1999.

Canto em si. São Paulo: Barcarola Editora, 2000.

. Lavradio. Rio de Janeiro: Myrrha, 2004.

Dasriasao mar oceano. Rio de Janeiro: Ágora da Ilha, 2000. 
Em meio às trilhas do Rio de Janeiro e de Trieste com a

Lírica urbana de Reynaldo Valinho Alvarez e Umberto Saba

Delia Cambeiro

Brasília: INL, 1980.

O solitário gesto de viver. Rio de Janeiro: Tempo Brasileiro; El aullido y los perros. In: El último día. Rio de Janeiro, Contraste, 2009.

ARGAN, Giulio Carlo. A bistória da arte como bistória da cidade. São Paulo: Martins Fontes, 2014.

ARISTOTELES. A política. Trad. Nestor Silveira Chaves. São Paul: Martins Fontes, 1998.

BENEVOLO, Leonardo. História da cidade. 4.ed. Trad. Sílvia Mazza. São Paulo: Perspectiva, 2009.

CAMBEIRO, Delia. A cidade e o olhar do poeta. Ensaio sobre a lírica urbana de ReynaldoValinho Alvarez. Rio de Janeiro: Contraste Editora, 2016.

CUNHA, Euclides da.Os Sertões. Rio de Janeiro: Francisco Alves, 1993.

KOTKIN, Joel. A cidade: uma história global. Trad. Rafael Mantovani. Rio de Janeiro: EditoraObjetiva, 2012.

LAVAGETTO, Mario (a cura). Per conoscere Saba. Milano, Mondadori, 1981.

LE GOFF, Jacques. Os intelectuais na Idade Média. 2. ed. Trad. MargaridaSérvuloCorreia. Lisboa: Gradiva, 1984.

MUSCETTA, Carlo (a cura). Antologia del "Canzoniere”. Torino: Giulio Einaudi Editore, 1972.

PLATÃO. República. Rio de Janeiro: Tecnoprint, sd.

POESIA VIVA. Entrevista com Reynaldo Valinho Alvarez. Rio de Janeiro: Editora UAP, ano 12, no 12, maio 2007.

SABA, Umberto. Mediterráneas. Trad. Esther Morillas. Valencia: Editorial PreTextos, 1991. Edición bilíngue.

SALMOS.Vitor Fridlin e Jairo Fridlin (Tradução e transliteração). 2 ed. São Paulo: Sêfer, 2001. 
Em meio às trilhas do Rio de Janeiro e de Trieste com a

Lírica urbana de Reynaldo Valinho Alvarez e Umberto Saba

Delia Cambeiro

TODOROV, Tzvetan. A literatura em perigo. Trad. Caio Meira. Rio de Janeiro: DIFEL, 2009. 